\title{
Learning About Voter Rationality
}

\author{
Running Head: Learning About Voter Rationality \\ Keywords: Campaigns and Elections, Rationality
}

Scott Ashworth

Harris School of Public Policy, University of Chicago

1155 E 60th St, Chicago IL 60637

email: sashwort@uchicago.edu

Ethan Bueno de Mesquita

Harris School of Public Policy, University of Chicago

1155 E 60th St, Chicago IL 60637

email: bdm@uchicago.edu

Amanda Friedenberg

W.P. Carey School of Business, Arizona State University

PO Box 879801

Tempe AZ 85287-9801

email: amanda.friedenberg@asu.edu

\footnotetext{
We are particularly indebted to Anthony Fowler. We have also benefited from comments by John Bullock, Alan Gerber, Greg Huber, Claire Lim, Andrew Little, Neil Malhotra, Alessia Russo, Ed Schlee, Mike Ting, Dustin Tingley, Stephane Wolton, seminar audiences at Cornell, Emory, the Juan March Institute, NYU, Princeton, Stanford, Vanderbilt, Virginia, Yale, and the participants in the EITM Summer Institutes at Princeton (2012) and Mannheim (2014). Friedenberg thanks Caltech for generous hospitality.
} 


\title{
Learning About Voter Rationality
}

\begin{abstract}
An important empirical literature evaluates whether voters are rational by examining how electoral outcomes respond to events outside the control of politicians, e.g., natural disasters or economic shocks. The argument is that rational voters should not base electoral decisions on such events, so evidence that these events affect electoral outcomes is evidence of voter irrationality. We show that such events can affect electoral outcomes, even if voters are rational and have instrumental preferences. The reason is that these events change voters' opportunities to learn new information about incumbents. Thus, identifying voter (ir)rationality requires more than just identifying the impact of exogenous shocks on electoral fortunes. Our analysis highlights systematic ways in which electoral fortunes are expected to change in response to events outside incumbents' control. Such results can inform empirical work attempting to identify voter (ir)rationality.
\end{abstract}

Word Count: 8998 
The literature on voter behavior has long been interested in evaluating voters' competence to fulfill their electoral responsibility. The early literature focused on whether voters are "sufficiently informed" (Campbell, Converse, Miller, and Stokes, 1960; Fair, 1978; Kinder and Sears, 1985; Popkin, 1991; Sniderman, Brody, and Tetlock, 1993; Lupia, 1994; Delli Carpini and Keeter, 1996). A more recent literature focuses on whether voters are "sufficiently rational" (Achen and Bartels, 2004; Wolfers, 2002; Leigh, 2009; Healy, Malhotra, and Mo, 2010; Achen and Bartels, 2016).

The voter rationality question is important for two reasons. First, the answer is central to normative debates about electoral democracy (Downs, 1957; Campbell et al., 1960; Key, 1966; Fiorina, 1981; Fair, 1978; Kinder and Sears, 1985; Popkin, 1991; Sniderman et al., 1993; Lupia, 1994; Delli Carpini and Keeter, 1996). Second, an extensive theoretical literature assumes voter rationality and claims to provide insight into a variety of political phenomena. ${ }^{1}$ If actual voter behavior dramatically diverges from the assumptions in those models, then there is reason to be skeptical about that research agenda.

An important empirical literature attempts to assess whether voters are indeed rational, examining the response of electoral outcomes to exogenous shocks outside the control of politicians. ${ }^{2}$ The idea is that, with rational voters, these shocks should not affect incumbents' electoral fortunes. While several studies find that incumbent electoral fortunes are unaffected by exogenous shocks to voter welfare (Abney and Hill, 1966; Ebeid and Rodden, 2006; Kayser and Peress, 2012), the dominant view is that incumbent electoral fortunes do suffer following such shocks (Achen and Bartels, 2004; Wolfers, 2002; Leigh, 2009; Healy et al., 2010; Achen and Bartels, 2016). The literature interprets this as evidence for voter irrationality. For instance, Achen and Bartels (2016, page 15) gloss their results with: "That suggests that [the voter's] ability (or their inclination) to make sensible judgments regarding credit and blame is highly circumscribed."

This paper takes the identified impact of shocks on electoral fortunes as given, and focuses on the lessons about voter rationality. We argue that - even if voters are rational-exogenous shocks should be expected to affect incumbents' electoral fortunes. Such shocks change the voters' opportunities to learn new information about the incumbent. We show that this change in voter information typically suffices to change both voter behavior and incumbent electoral fortunes. Importantly, this occurs even if voters only have instrumental preferences-i.e., preferences for governance outcomes - and do not blame the incumbent for events outside of her control. Hence, our model suggests that evidence of electoral fortunes responding to exogenous shocks does not, on its own, entail the conclusion that voters are irrational.

\footnotetext{
${ }^{1}$ See, e.g., Banks and Sundaram (1993); Lohmann (1998); Persson and Tabellini (2000); Canes-Wrone, Herron, and Shotts (2001); Besley and Burgess (2002); Coate (2004); Maskin and Tirole (2004); Ashworth (2005, 2006); Ashworth and Bueno de Mesquita (2006, 2008); Besley (2006); Besley and Prat (2006); Myerson (2006); Gehlbach (2007); Gordon, Huber, and Landa (2007); Fox and Van Weelden (2010); Daley and Snowberg (2011); Fox and Jordan (2011); Fox and Van Weelden (2012); Fox and Stephenson (2011, 2015); Almendares and Le Bihan (2015); Eggers (2015).

${ }^{2}$ These shocks typically take the form of either a natural disasters (Abney and Hill, 1966; Achen and Bartels, 2004; Healy and Malhotra, 2010; Healy et al., 2010; Bechtel and Hainmueller, 2011; Gasper and Reeves, 2011; Cole, Healy, and Werker, 2012; Huber, Hill, and Lenz, 2012; Chen, 2013) or economic shocks originating outside of the local economy (Ebeid and Rodden, 2006; Wolfers, 2002; Leigh, 2009; Kayser and Peress, 2012).
} 
An example will help give a sense of our argument. A hurricane is a random shock, outside the control of the incumbent. But the damage the hurricane causes depends on the quality of infrastructure maintenance, emergency preparedness, and so on. These, in turn, depend on the quality of governance.

Suppose politicians are either high quality or low quality. Voters want to elect high quality politicians, who are expected to provide better governance outcomes in the future. At the same time, high quality incumbents are better at storm preparation than are low quality incumbents. Thus, the presence of a hurricane gives voters the opportunity to learn about the quality of the incumbent which, in turn, affects their expectations of future government performance.

To make this more concrete, suppose that the hurricane provides voters with stark information: If a hurricane does not occur, voters remain uninformed about preparedness. But, if a hurricane does occur, voters observe the effects of the storm, perfectly learning the level of preparedness. ${ }^{3}$ Absent a hurricane, the voters learn nothing new about the incumbent's quality. But, with a hurricane, they can infer her quality. Rational voters should use this additional information about the incumbent's quality in forming their assessments of the incumbent's expected future performance. As a result, a hurricane will influence rational voters' electoral decisions even though they don't blame the incumbent for the hurricane.

This change in voter behavior can affect the incumbent's expected electoral fortunes. Suppose voters believe that the incumbent is, ex ante, more likely to be high quality than is a future electoral challenger. Then, if there is no hurricane, they reelect the incumbent. If, however, there is a hurricane, reelection depends on preparedness. With high preparedness, voters learn the incumbent is high quality and reelect her. With low preparedness, voters learn the incumbent is low quality and replace her. By giving the voters new information, the hurricane creates the possibility that the incumbent will lose - something that does not happen absent a hurricane.

What would an empiricist analyzing data generated by this example find? Hurricanes occur randomly in some locations. In locations that do not have a hurricane, the empiricist will find a reelection rate of one. In locations that do have a hurricane, the empiricist will find a reelection rate equal to the share of high quality incumbents - a number less than one. Hence - just as in the literature - the empiricist correctly concludes that hurricanes harm incumbent electoral fortunes even though incumbents bear no responsibility for the hurricanes. But this observation is not evidence of voter irrationality. In fact, quite the opposite: it results from voters rationally trying to select high quality politicians.

We build on this simple example. Specifically, we assume voter rationality and use that hypothesis to deduce how incumbent electoral fortunes should be affected by exogenous shocks. We show that, in many environments, exogenous shocks to voter welfare should be expected to impact incumbent electoral fortunes; in those environments, evidence that electoral fortunes do not suffer would be evidence of voter irrationality. Likewise, in some (but not all) of those environments, incumbent electoral fortunes should decline with exogenous shocks; in those environments, evidence

\footnotetext{
${ }^{3}$ Our formal model does not use such stark informational differences, but they make the point as clearly as possible.
} 
that they do in fact decline supports the rational voter hypothesis.

Our analysis highlights systematic ways in which electoral fortunes should be impacted by events outside the incumbents' control. In particular, how electoral fortunes should be impacted depends on both how governance outcomes are produced and on prior beliefs about candidates. Thus, identifying voter (ir)rationality requires more than simply identifying the impact of exogenous shocks on electoral fortunes. The hope is that the results here can serve to guide future empirical work and improve the identification of voter (ir)rationality.

In what follows we focus on how voters learn about incumbent politicians from exogenous shocks, abstracting away from the fact that incumbents may also engage in disaster relief. Such relief efforts might also affect the amount of information voters learn about the incumbent and, thereby, affect the incumbent's electoral fortunes (positively or negatively) (Ashworth, Bueno de Mesquita, and Friedenberg, 2017). Hence, the potential for disaster relief further complicates researchers' ability to identify voter (ir)rationality. ${ }^{4}$ This fact is important for the literature: A series of papers finds that controlling for disaster relief mitigates the correlation between exogenous shocks and incumbent electoral fortunes (Healy and Malhotra, 2010; Bechtel and Hainmueller, 2011; Gasper and Reeves, 2011; Cole et al., 2012). These results are interpreted as evidence of voter rationality. But such inferences are also premature. Whether this is or is not evidence of voter rationality, again, depends on how governance outcomes are produced and prior beliefs.

\section{Motivating Examples}

We will analyze how disasters affect voter behavior and electoral fortunes, using the canonical Bayesian learning framework (Achen, 1992; Bartels, 1993; Gerber and Green, 1999). We adapt the specific model in Wolfers (2002), since it speaks directly to the issue of observable shocks and electoral fortunes. This specific model justifies the conventional wisdom: if voters are rational, electoral fortunes do not depend on observable shocks. We then show that this conclusion in favor of the conventional wisdom is not robust to a minor modification to the example. The comparison of these two examples raises a series of questions, to be addressed by our subsequent analysis.

\subsection{Example 1: When Shocks Have No Effect}

There are two politicians, an Incumbent and a Challenger. Each is either a good type $(\bar{\theta})$ or a bad type $(\underline{\theta})$. The probability that Politician $P$ is a good type is $\pi_{P} \in(0,1)$. (The canonical model has normally distributed types. Having two types is the only change we make to the canonical model. It simplifies the later analysis.)

In each period, the Voter observes a governance outcome (e.g., a level of public goods provided). This outcome is the output of a production function that depends on the Incumbent's type and two shocks: the observable disaster and an unobservable idiosyncratic shock. Specifically, the

\footnotetext{
${ }^{4}$ Gailmard and Patty (2014) use a different model of accountability make a related but distinct point: Rational voters may reward politicians who do not engage in disaster prevention but do engage in disaster relief.
} 
governance outcome in period $t=1,2$ is given by

$$
g_{t}=\theta_{t}-\omega_{t}+\epsilon_{t},
$$

where, in period $t, \theta_{t}$ is the type of the Incumbent, $\omega_{t}$ is the disaster intensity, and $\epsilon_{t}$ is the idiosyncratic shock. The idiosyncratic shock $\epsilon_{t}$ is drawn from the standard normal distribution. All random variables are independent of one another.

Between the two governance periods, there is an election. In the election, the Voter reelects the Incumbent if the Voter's posterior belief that the Incumbent is a good type is higher than his prior belief that the Challenger is a good type. Using Bayes' rule, the Voter reelects if and only if

$$
\frac{\pi_{I} \varphi\left(g_{1}+\omega_{1}-\bar{\theta}\right)}{\pi_{I} \varphi\left(g_{1}+\omega_{1}-\bar{\theta}\right)+\left(1-\pi_{I}\right) \varphi\left(g_{1}+\omega_{1}-\underline{\theta}\right)} \geq \pi_{C},
$$

where $\varphi$ is the pdf of the standard normal distribution.

It is worth pausing here to see what the rational Voter is doing. The Voter prefers the candidate with the highest type. He does not observe the type of each candidate. But, he does observe the disaster intensity $\omega_{1}$ and the governance outcome $g_{1}$. Note, $g_{1}$ is a signal of the Incumbent's typeone that is biased by the disaster intensity $\omega_{1}$. The Voter uses this information to try to learn about the Incumbent's type $\theta_{I}$. He does so by "filtering out" the bias caused by the disaster - adding $\omega_{1}$ to $g_{1}$-and then forming his posterior beliefs.

Rearranging Equation (1), the voter reelects if and only if

$$
\frac{\varphi\left(g_{1}+\omega_{1}-\bar{\theta}\right)}{\varphi\left(g_{1}+\omega_{1}-\underline{\theta}\right)} \geq \frac{\pi_{C}}{1-\pi_{C}} \frac{1-\pi_{I}}{\pi_{I}}
$$

The left-hand side of this inequality is strictly increasing and continuous in $g_{1}+\omega_{1} \cdot{ }^{5}$ So there is a unique number, $\rho$, such that Equation (2) holds with equality if and only if $g_{1}+\omega_{1}=\rho$.

To see how this model gives rise to the standard intuitions, we show analogues of Wolfers's (2002) claim that "events unrelated to a governor's competence should have no effect on the voting decisions of rational agents" [p. 4, emphasis in original].

First, the Voter adopts a reelection threshold that governance outcomes must meet. He adjusts that threshold to exactly offset the effect of disaster intensity. To see this, suppose the disaster intensity is $\omega_{1}$. Then $\hat{g}\left(\omega_{1}\right) \equiv \rho-\omega_{1}$ represents the Voter's reelection threshold. The Voter reelects if and only if

$$
g_{1} \geq \hat{g}(\omega)=\rho-\omega_{1}
$$

So, if a disaster reduces governance outcomes by 1 unit, the Voter reduces the reelection threshold by exactly 1 unit.

Second, the Incumbent's electoral fortunes do not depend on the presence or magnitude of a

\footnotetext{
${ }^{5}$ This follows from the monotone-likelihood ratio property of the normal distribution.
} 
disaster. The probability the incumbent is reelected is the probability that $g_{1} \geq \hat{g}\left(\omega_{1}\right)$. That is,

$$
\operatorname{Pr}\left(\theta_{I}-\omega_{1}+\epsilon_{1} \geq \hat{g}\left(\omega_{1}\right)\right)=\operatorname{Pr}\left(\theta_{I}+\epsilon_{1} \geq \rho\right)
$$

That this probability is constant in $\omega_{1}$ corresponds to the standard intuition that incumbent electoral fortunes are not affected by disasters.

\subsection{Example 2: When Shocks Have An Effect}

In the above example, the governance outcome $g_{t}$ was determined by a production function that is additively separable in type and disaster intensity (i.e., $\theta-\omega_{t}+\varepsilon_{t}$ ). As such, the Incumbent's type does not interact with the level of disaster intensity in the production of governance outcomes. This assumption is not made for verisimilitude, but for tractability: It yields an elegant model that is easy to work with.

Given the elegance of the additively separable model, there is a temptation to conclude that its implications must be robust. If correct then, given extant empirical findings, the model suggests voters are irrational. But if additive separability is driving the results, there may be reason to be concerned about this interpretation.

Below we take a first step toward showing that the impression of robustness is spurious. To do so, we make one change to Example 1. The governance outcome in period $t$ is now

$$
g_{t}=\left(\theta_{t}-\omega_{t}\right)^{k}+\epsilon_{t}
$$

where $k>0$ and each possible disaster intensity $\omega_{t}$ is between 0 and $\underline{\theta}$. (This ensures that governance outcomes are decreasing in disaster intensity.) The additively separable model is the special case where $k=1$.

Repeating the logic that led to Equation (2), the Voter reelects the Incumbent if and only if

$$
\frac{\varphi\left(g_{1}-\left(\bar{\theta}-\omega_{1}\right)^{k}\right)}{\varphi\left(g_{1}-\left(\underline{\theta}-\omega_{1}\right)^{k}\right)} \geq \frac{\pi_{C}}{1-\pi_{C}} \frac{1-\pi_{I}}{\pi_{I}} .
$$

Using the formula for the PDF of the standard normal, the Voter reelects if and only if

$$
\frac{e^{-\left(g_{1}-\left(\bar{\theta}-\omega_{1}\right)^{k}\right)^{2}}}{e^{-\left(g_{1}-\left(\underline{\theta}-\omega_{1}\right)^{k}\right)^{2}}} \geq \frac{\pi_{C}}{1-\pi_{C}} \frac{1-\pi_{I}}{\pi_{I}} .
$$

Taking logs on both sides, we can calculate the Voter's reelection threshold:

$$
\hat{g}\left(\omega_{1}\right)=\frac{\log \frac{\pi_{C}}{1-\pi_{C}} \frac{1-\pi_{I}}{\pi_{I}}}{2(\bar{\theta}-\omega)^{k}-2(\underline{\theta}-\omega)^{k}}+\frac{(\bar{\theta}-\omega)^{k}+(\underline{\theta}-\omega)^{k}}{2} .
$$

The probability the Incumbent is reelected is the probability that $g_{1} \geq \hat{g}_{1}\left(\omega_{1}\right)$, or, equivalently, 
the probability that $\left(\theta_{I}-\omega_{1}\right)^{k}+\epsilon_{1} \geq \hat{g}\left(\omega_{1}\right)$. This can be written as

$$
1-\left[\pi_{I} \Phi\left(\hat{g}\left(\omega_{1}\right)-\left(\bar{\theta}-\omega_{1}\right)^{k}\right)+\left(1-\pi_{I}\right) \Phi\left(\hat{g}\left(\omega_{1}\right)-\left(\underline{\theta}-\omega_{1}\right)^{k}\right)\right]
$$

where $\Phi$ is the CDF of the standard normal distribution.

From Equations (3)-(4) we can compute the probability of reelection as a function of disaster intensity $\omega_{1}$. Figure 1 does so for two values of $\left(\pi_{I}, \pi_{C}\right)$ and three values of $k$. The left-hand cell is a case where $\pi_{I}=\frac{1}{3}$ and $\pi_{C}=\frac{1}{2}$, so that ex ante the Challenger is more likely than the Incumbent to be a high type. The right-hand cell is a case where $\pi_{I}=\frac{2}{3}$ and $\pi_{C}=\frac{1}{2}$, so that ex ante the Incumbent is more likely than the Challenger to be a high type. Within each cell, there are graphs of the probability of reelection for $k=\frac{1}{2}, k=1$, and $k=\frac{3}{2}$.

[Figure 1 about here.]

The figures confirm our analysis of Example 1. When $k=1$ the probability of reelection is constant in $\omega_{1}$. But this is not the case when $k=\frac{1}{2}$ or when $k=\frac{3}{2}$. In those cases, $\left(\pi_{I}, \pi_{C}\right)$ influences the effect of disaster intensity on the probability of reelection. When $k=\frac{1}{2}$, the probability of reelection is increasing in the left-hand cell and decreasing in the right-hand cell. When $k=\frac{3}{2}$ the situation is reversed.

\subsection{Back to the Question}

The examples support different conclusions about voter rationality. On the one hand, if $k=1$ and electoral fortunes respond to observable shocks, then there is evidence of voter irrationality. On the other hand, if $k$ is either $\frac{1}{2}$ or $\frac{3}{2}$ and voters are rational, then electoral fortunes should respond to observable shocks.

A priori, there is no principled reason to assume some particular value of $k$. As such, it is difficult to know what the model implies about the relationship between existing empirical results and inferences about voter rationality. Taking a view on the correct value of $k$ requires a substantive argument about which value best approximates the world being represented by the model. But, thus far, the choice of $k$ appears entirely unmotivated.

To start thinking about this issue, recall the hurricane example from the Introduction. There, disaster intensity altered how much information the voters had about the incumbent's type: When there was no disaster $\left(\omega_{1}=0\right)$, the voter had no information about preparedness. But when there was a disaster $\left(\omega_{1}>0\right)$, the voter had information about preparedness. As a result, disaster intensity could affect electoral fortunes. In what follows, we will show that this qualitative feature of the political environment-how disaster intensity affects voter information - is the key for understanding more generally how disasters affect voter behavior and incumbent electoral fortunes.

The results clarify that specifying the value $k$ entails a substantive assumption - one that directly translates into an assumption about qualitative features of the political environment. In particular, it is an assumption that determines how disasters affect voter information: If $k<1$, 
then larger disaster intensities imply that the Voter learns more information about the Incumbent's type. If $k>1$, then larger disaster intensities imply that the Voter learn less information about the Incumbent's type. The case of $k=1$ is the unique instance in which disaster intensity has no effect on how much information the Voter learns. Moreover, as we will show, it is this knife-edge case - where disasters provide no information about the Incumbent's type - that is responsible for the conventional wisdom, i.e., that electoral fortunes are unaffected by disasters.

Once we establish these qualitative results, we will return to the substantive question: What information would an empiricist need to make inferences about voter rationality? Our results will show that, in all but the additively separable case, simply observing a relationship between electoral fortunes and observable shocks is not sufficient. But we will also be able to say something more constructive about what additional information would suffice - e.g., information about $\pi_{I}, \pi_{C}$, or about how governance outcomes are produced.

\section{The General Model}

This section generalizes the model from Section 1.1, backing away from specific functional forms. This allows for a more qualitative approach. Specifically, it allows us to understand the effect of observable shocks on the Voter's information about the Incumbent's type. This will, in turn, permit us to provide a transparent link between, on the one hand, substantively interpretable features of the environment and, on the other hand, a formal measure of informativeness.

\subsection{Set Up}

There is an Incumbent $(I)$, a Challenger $(C)$, and a Voter. We refer to each Politician $(P)$ as "she" and the Voter as "he." In each of two governance periods, the Voter receives a governance outcome that depends on the type of the Politician in office, an observable natural disaster, and an unobservable idiosyncratic shock. There is an election between the governance periods.

The set of types is $\{\underline{\theta}, \bar{\theta}\}$, where $\underline{\theta}$ is the bad type and $\bar{\theta}>\underline{\theta}$ is the good type. Write $\pi_{P} \in(0,1)$ for the probability that Politician $P$ is type $\bar{\theta}$. These probabilities are commonly understood by the players. We will say that the Incumbent enters the first governance period ahead if $\pi_{I}>\pi_{C}$ and enters the first governance period behind if $\pi_{C}>\pi_{I}$.

The intensity of the natural disaster in period $t$ is $\omega_{t} \in \Omega$ where $\Omega=\mathbb{R}$. Each $\omega_{t}$ is the realization of a random variable that is independent of the Politician's ability. (The particular distribution will not be relevant.)

The governance outcome in a period is determined by a production technology and a random shock. The production function $f:\{\underline{\theta}, \bar{\theta}\} \times \Omega \rightarrow \mathbb{R}$ is strictly increasing in type $(\theta)$ and is strictly decreasing in disaster intensity $(\omega)$. We will be interested in whether natural disasters amplify or mute the effect of type on governance outcomes.

Definition 2.1. Fix $\omega^{\prime}>\omega$ 
(i) Disasters amplify the effect of type on governance outcomes at $\left(\omega, \omega^{\prime}\right)$ if

$$
f\left(\bar{\theta}, \omega^{\prime}\right)-f\left(\underline{\theta}, \omega^{\prime}\right)>f(\bar{\theta}, \omega)-f(\underline{\theta}, \omega)
$$

(ii) Disasters mute the effect of type on governance outcomes at $\left(\omega, \omega^{\prime}\right)$ if

$$
f\left(\bar{\theta}, \omega^{\prime}\right)-f\left(\underline{\theta}, \omega^{\prime}\right)<f(\bar{\theta}, \omega)-f(\underline{\theta}, \omega)
$$

Say that disasters amplify (resp. mute) the effect of type if disasters amplify (resp. mute) the effect of type at each $\left(\omega, \omega^{\prime}\right)$ with $\omega^{\prime}>\omega .{ }^{6}$ Observe that, when the production function is additive, $f\left(\bar{\theta}, \omega^{\prime}\right)-f\left(\underline{\theta}, \omega^{\prime}\right)=f(\bar{\theta}, \omega)-f(\underline{\theta}, \omega)$ for all $\omega, \omega^{\prime}$. Thus, in that case, disasters neither amplify nor mute the effect of type (at any $\left(\omega, \omega^{\prime}\right)$ ).

The governance outcome in period $t$ is given by $g_{t}=f\left(\theta_{t}, \omega_{t}\right)+\epsilon_{t}$, where $\theta_{t}$ is the type of the Politician in office in period $t, \omega_{t}$ is the level of disaster intensity in period $t$, and $\epsilon_{t}$ is the random shock in period $t$.

Each $\epsilon_{t}$ is the realization of a random variable. These random variables are independent of each other, of the Politicians' abilities, and of the disaster intensities. They are distributed according to an absolutely continuous $\mathrm{CDF}, \Phi$, with a continuously differentiable PDF, $\phi$. This distribution satisfies three additional requirements: First, for each $x>x^{\prime} \geq 0$, the associated likelihood ratio defined by

$$
g \mapsto \frac{\phi(g-x)}{\phi\left(g-x^{\prime}\right)}
$$

is onto with non-zero derivatives. Second, the distribution satisfies the (strict) monotone likelihood ratio property (MLRP) relative to all possible realizations of production: If $x>x^{\prime}$, then the associated likelihood ratio

$$
\frac{\phi(g-x)}{\phi\left(g-x^{\prime}\right)}
$$

is strictly increasing in $g$. Third, the PDF is symmetric: for each $x \in \mathbb{R}, \phi(x)=\phi(-x)$. (The standard normal PDF, $\varphi$, satisfies these conditions.)

Prior to the game being played, Nature determines the realizations of each Politician's type and of the random shocks (in all periods). These realizations are not observed by any of the players. Figure 2 depicts the timeline: In the initial governance period, the Voter observes the disaster intensity and the governance outcome. This leads to the electoral stage, in which the Voter chooses to reelect the Incumbent or replace her with a Challenger. The winner of the election is the Politician in office in the second governance period. Again, the Voter observes the disaster intensity and the governance outcome, $g_{2}$.

[Figure 2 about here.]

\footnotetext{
${ }^{6}$ This is a global requirement. We will make use of it in Section 4 . There, it can be relaxed to require that disasters amplify (resp. mute) the effect of type at $\left(\omega, \omega^{\prime}\right)$ and, for each $\omega^{\prime \prime} \in\left(\omega, \omega^{\prime}\right)$, disasters amplify (resp. mute) the effect of type at both $\left(\omega, \omega^{\prime \prime}\right)$ and $\left(\omega^{\prime \prime}, \omega^{\prime}\right)$.
} 
The Voter's payoffs are the sum of governance outcomes in the two periods.

\subsection{Comments on the Model}

This is a model of "pure selection" - the governance outcome is determined entirely by the politician's type, the disaster, and the shock. The politician in office cannot take costly actions to affect the governance outcome. This assumption is just for simplicity, and does not affect the message of the paper. To see why, recall a well-known feature of agency models of elections: At the time of the election, rational voters are concerned only with electing the politician who affords the highest expected future performance. Thus, the fact that politicians may be able to undertake costly actions does not change the fact that, at the point of the election, rational voter behavior is determined by voter learning about incumbent quality (Fearon, 1999). When politicians can take actions, the actions can also provide information about the incumbent's type, i.e., above the information provided by the disaster itself (Ashworth et al., 2017). This can further complicate the voters' inference problem. But, because the logic of voter behavior does not change in a fundamental way, our main insights do not change.

When we move away from the additive model, disasters can amplify or mute the effect of type. So, it is important to understand what amplify and mute mean, substantively. If disasters amplify the effect of type, then incumbent competence has a larger effect on governance outcomes when disasters are large (versus when they are small). The hurricane example in the Introduction is an example of such amplification. By contrast, if disasters mute the effect of type, then incumbent competence has a smaller effect on governance outcomes when disasters are large (versus when they are small). For instance, suppose that good types are better at attracting investment. In normal times, good types will oversee better economic performance. But a natural disaster might stop investment, irrespective of the type of the incumbent. In this case, disasters mute the effect of type.

\subsection{Analysis}

As in the additive model, the Voter reelects the Incumbent only if the first-period governance outcome, $g_{1}$, is greater than or equal to the reelection threshold $\hat{g}\left(\omega_{1}\right)$. This is the (unique) number that solves

$$
\frac{\phi\left(\hat{g}\left(\omega_{1}\right)-f\left(\bar{\theta}, \omega_{1}\right)\right)}{\phi\left(\hat{g}\left(\omega_{1}\right)-f\left(\underline{\theta}, \omega_{1}\right)\right)}=\frac{1-\pi_{I}}{\pi_{I}} \frac{\pi_{C}}{1-\pi_{C}} .
$$

This is the analogue of Equation (2) in the additively separable model, where $\hat{g}\left(\omega_{1}\right)=\rho-\omega_{1}$.

For the analysis of Voter behavior, it will be convenient to work with the loglikelihood ratio,

$$
\ell\left(g, \omega_{1}\right) \equiv \log \frac{\phi\left(g-f\left(\bar{\theta}, \omega_{1}\right)\right)}{\phi\left(g-f\left(\underline{\theta}, \omega_{1}\right)\right)}
$$


We can, equivalently, define $\hat{g}\left(\omega_{1}\right)$ as the solution to $\ell\left(\hat{g}\left(\omega_{1}\right), \omega_{1}\right)=\beta\left(\pi_{I}, \pi_{C}\right)$, where

$$
\beta\left(\pi_{I}, \pi_{C}\right) \equiv \log \left[\frac{1-\pi_{I}}{\pi_{I}} \frac{\pi_{C}}{1-\pi_{C}}\right] .
$$

Observe that $\beta\left(\pi_{I}, \pi_{C}\right)<0$ if the Incumbent is ahead and $\beta\left(\pi_{I}, \pi_{C}\right)>0$ if the Incumbent is behind. The CDF of governance outcomes is given by

$$
\Gamma(g ; \omega)=\pi_{I} \Phi(g-f(\bar{\theta}, \omega))+\left(1-\pi_{I}\right) \Phi(g-f(\underline{\theta}, \omega)) .
$$

Since the Voter adopts $\hat{g}(\omega)$ as the reelection threshold, the ex ante probability that the Incumbent is reelected given disaster intensity $\omega$ is $1-\Gamma(\hat{g}(\omega) ; \omega)$. (This is the analogue of Equation (4) from Example 2.)

\section{Voter Behavior}

Section 1 showed that, when production is additively separable, the Voter's reelection threshold is monotone in disaster intensity: Worse disasters are associated with lower reelection thresholds. This is intuitive. For any given level of noise, a more intense disaster lowers the governance outcome. So, an increase in disaster intensity makes the distribution of outcomes "worse." As such, the Voter might reelect the Incumbent after observing a large disaster and a particular governance outcome, despite the fact that he would have replaced the Incumbent had that same governance outcome followed a minor disaster.

Indeed, in the additive model, a stronger property holds: The Voter's reelection threshold changes to exactly offset the effect of the disaster on the distribution of outcomes. This fact appears to fit with the intuition motivating much of the empirical literature. But we will see that, when disasters amplify or mute the effect of type, this conclusion is, quite generally, incorrect. (See Propositions 3.1-3.2.) To get there, it will be useful to be more precise about what we mean by Voter behavior offsetting the effect of a disaster.

\subsection{Neutral News and Informativeness}

For any given disaster intensity, $\omega$, there is an outcome $g=\nu(\omega)$ such that, when the Voter observes $\nu(\omega)$, his posterior belief about the Incumbent's type is unchanged from his prior.

Definition 3.1. For any given disaster intensity $\omega$, the neutral news outcome, written $\nu(\omega)$, is the outcome at which the Voter's posterior belief about the Incumbent's type is equal to the prior belief about the Incumbent's type.

Call outcomes greater than the neutral news outcome (i.e., $g>\nu(\omega)$ ) good news outcomes and call outcomes less than the neutral news outcome (i.e., $g<\nu(\omega))$ bad news outcomes. Good news outcomes raise the Voter's posterior belief about the Incumbent's type and bad news outcomes lower the Voter's posterior belief about the Incumbent's type. (These facts follow from the MLRP.) 
Applying Bayes' rule, the definition of neutral news implies that

$$
\frac{\phi(\nu(\omega)-f(\bar{\theta}, \omega))}{\phi(\nu(\omega)-f(\underline{\theta}, \omega))}=1 .
$$

Equation (8) and symmetry of $\phi$ imply that we can write the neutral news outcome as

$$
\nu(\omega)=\frac{f(\bar{\theta}, \omega)+f(\underline{\theta}, \omega)}{2} .
$$

An implication of this explicit solution is that the neutral news outcome is decreasing in disaster intensity - the more intense the disaster, the lower the neutral news outcome.

Refer back to the additive production function in Section 1: There, the neutral news outcome is $\nu(\omega)=\frac{\bar{\theta}+\underline{\theta}}{2}-\omega$, and the reelection threshold is $\hat{g}(\omega)=\rho-\omega$. So, if the disaster intensity increases from $\omega$ to $\omega^{\prime}$, both the neutral news outcome and the reelection threshold decrease by the same amount (specifically, by $\left|\omega^{\prime}-\omega\right|$ ). In this sense, the change in the Voter's reelection threshold exactly offsets the change in disaster intensity.

Definition 3.2. Let $\omega^{\prime}>\omega$. Voter behavior exactly offsets the effect of disasters if:

$$
\hat{g}\left(\omega^{\prime}\right)=\hat{g}(\omega)+\nu\left(\omega^{\prime}\right)-\nu(\omega) .
$$

Voter behavior more than offsets the effect of disasters if the left-hand side is less than the righthand side and less than offsets the effect of disasters if the left-hand side is greater than the right-hand side.

In the additive model, Voter behavior exactly offsets the effect of disasters. But this does not hold more generally:

Proposition 3.1. Fix $\omega^{\prime}>\omega$ so that disasters amplify (respectively, mute) the effect of type at $\left(\omega, \omega^{\prime}\right)$. Then, Voter behavior exactly offsets the effect of disaster if and only if $\pi_{I}=\pi_{C}$.

Proposition 3.1 implies that, moving beyond the additive model, Voter behavior offsets the effect of disaster only in the degenerate case where the Incumbent and Challenger are ex ante identical. In fact, we will see that, without additive separability, the Voter's reelection threshold need not even be monotonic with disaster intensity-larger disasters need not lead the Voter to lower his reelection threshold. (See Figure 6 below.)

The key is that, for any production function that is not additively separable, there are two effects at work. Not only does a change in disaster intensity shift the neutral news outcome, it also changes how informative governance outcomes are about the Incumbent's type (in the sense of Blackwell, 1951). ${ }^{7}$

\footnotetext{
${ }^{7}$ Each disaster intensity induces a signal about the Incumbent's type, i.e., a mapping from unobserved states (Incumbent type and noise) to governance outcomes. A particular observed governance outcome is the realization of that signal. One signal is Blackwell more informative than another if the distribution of posteriors under the first signal is a mean-preserving spread of the distribution of posteriors under the second signal (Gollier, 2001, pp. 370-371).
} 
To illustrate these two effects, fix a disaster intensity $\omega$. Each type $\theta$ generates a distribution on outcomes, i.e., the probability density of an outcome $g=f(\theta, \omega)+\epsilon$ is the probability density of $\epsilon=g-f(\theta, \omega)$. The Voter's challenge is to figure out how likely it is that a particular governance outcome came from the distribution associated with the good type (namely, $\phi(g-f(\bar{\theta}, \omega))$ ) versus the distribution associated with the bad type (namely, $\phi(g-f(\underline{\theta}, \omega)))$.

In Figure 3, the top picture depicts the densities of outcomes outcomes associated with the good type and the bad type when the disaster intensity is $\omega$. The bottom picture depicts the densities of outcomes when the disaster intensity is $\omega^{\prime}>\omega$. In each picture, the density to the left corresponds to the bad type and the density to the right corresponds to the good type.

[Figure 3 about here.]

First, observe the neutral news effect of disaster intensity. Because disaster intensity is higher under $\omega^{\prime}$ versus $\omega$, the mean of each density is lower under $\omega^{\prime}$ versus $\omega$, i.e., for each type $\theta$, $f\left(\theta, \omega^{\prime}\right)<f(\theta, \omega)$. Consequently, the neutral news outcome is lower under $\omega^{\prime}$ versus $\omega$. (Equation (8) says that the neutral news outcome is found at the intersection of these two densities.)

Now observe the informativeness effect. Figure 3 shows the case where disasters amplify the effect of type at $\left(\omega, \omega^{\prime}\right)$. Consequently, the distance between the means of the two densities is larger for $\omega^{\prime}$ versus $\omega$. This increased distance between the two densities corresponds to an improvement in Voter information - informally, when the means of the densities are further apart, it is easier for the Voter to determine which density a given outcome came from.

It will be convenient to measure informativeness as:

$$
\iota(\omega)=\frac{f(\bar{\theta}, \omega)-f(\underline{\theta}, \omega)}{2} .
$$

By Theorem 3.1 of Ashworth et al. (2017), if $\omega^{\prime}>\omega$ and $\iota\left(\omega^{\prime}\right)>\iota(\omega)$, then outcomes are more Blackwell-informative about the Incumbent's type when the disaster intensity is $\omega^{\prime}$ versus when the disaster intensity is $\omega$. It's easy to see that disasters amplify (resp. mute) the effect of type if and only if $\iota(\cdot)$ is increasing (resp. decreasing) in disaster intensity. Consequently, governance outcomes are more informative (resp. less informative) following larger disasters, if disasters amplify (resp. mute) the effect of type.

Observe that:

$$
f(\bar{\theta}, \omega)=\nu(\omega)+\iota(\omega) \text { and } \quad f(\underline{\theta}, \omega)=\nu(\omega)-\iota(\omega) .
$$

So, we can express the loglikelihood ratio (Equation (6)) in terms of the variables $(g, \nu(\omega), \iota(\omega))$,

$$
\ell(g, \omega)=\log \frac{\phi(g-\nu(\omega)-\iota(\omega))}{\phi(g-\nu(\omega)+\iota(\omega))} .
$$

This will allow us to separately analyze how changing disaster intensity changes the Voter's behavior via a change in the neutral news outcome $\nu(\omega)$ versus a change in informativeness $\iota(\omega)$. 


\subsection{The Neutral News Effect}

Increasing disaster intensity from $\omega$ to $\omega^{\prime}$ decreases the neutral news outcome from $\nu(\omega)$ to $\nu\left(\omega^{\prime}\right)$. To understand how this effect impacts the reelection rule, consider a thought experiment in which there is a change to the neutral news outcome with no corresponding change in information. To do so, define a new function:

$$
N(g)=\log \frac{\phi\left(g-\nu\left(\omega^{\prime}\right)-\iota(\omega)\right)}{\phi\left(g-\nu\left(\omega^{\prime}\right)+\iota(\omega)\right)} .
$$

(Note, $N(\cdot)$ depends on the disaster intensities $\omega, \omega^{\prime}$; we surpress this dependence in the notation.) This neutral news-shifted function is obtained from the loglikelihood ratio $\ell(\cdot, \omega)$ by decreasing the neutral news outcome from $\nu(\omega)$ to $\nu\left(\omega^{\prime}\right)$, but leaving the informativeness unchanged as $\iota(\omega)$. That is, it is obtained by shifting $\ell(\cdot, \omega)$ up. (Lemma B.1 shows that $N(\cdot)>\ell(\cdot, \omega)$.)

[Figure 4 about here.]

Figure 4 depicts this upward shift. The dark solid line is the loglikelihood function $\ell(\cdot, \omega)$; it is increasing because of the MLRP. The light solid line is the neutral news-shifted function $N(\cdot)$. The neutral news outcome, $\nu(\omega)$, is the outcome where the $\log$ likelihoood ratio $\ell(\cdot, \omega)$ equals zero. The reelection threshold, $\hat{g}(\omega)$, is the outcome where the $\log$ likelihood ratio $\ell(\cdot, \omega)$ equals $\beta\left(\pi_{I}, \pi_{C}\right)$. (Refer to Section 2.3.) This figure shows a case where the Incumbent is ahead-i.e., ex-ante the Incumbent is more likely than the Challenger to be a good type-so $\beta\left(\pi_{I}, \pi_{C}\right)<0$. Consequently, the reelection threshold, $\hat{g}(\omega)$, is below the neutral news outcome, $\nu(\omega)$. (So, the Incumbent can be reelected even if the governance outcome is somewhat bad news.) Because $N(\cdot)$ lies above $\ell(\cdot, \omega)$, $N(\cdot)$ intersects $\beta\left(\pi_{I}, \pi_{C}\right)$ at a governance outcome, $n$, that is below the reelection threshold $\hat{g}(\omega)$. (Because $N$ depends on $\omega$ and $\omega^{\prime}$, so does $n$; again, we surpress this dependence.)

Notice, if the Voter accounted for the change in the neutral news outcome but ignored any change in informativeness, he would adopt $n$ as a threshold for reelection. With this in mind, we refer to $n$-i.e., the outcome with $N(n)=\beta\left(\pi_{I}, \pi_{C}\right)$ - as the neutral news-shifted threshold. (The neutral news-shifted threshold $n$ is not to be confused with the neutral news outcome $\nu(\omega)$.) The fact that the neutral news-shifted threshold $n$ lies below $\hat{g}(\omega)$ reflects the intuition with which we began. When the disaster intensity increases, the Voter wants to "filter out" the mechanical effect of the shock on the distribution of outcomes - i.e., he doesn't blame the Incumbent for events outside of her control. If he ignores the effect of informativeness, then he is willing to reelect the Incumbent at a worse governance outcome. Moreover, the difference between the Voter's reelection threshold $\hat{g}(\omega)$ and the neutral news-shifted threshold $n$ is exactly the change in the neutral news outcome, i.e., $\hat{g}(\omega)-n=\nu(\omega)-\nu\left(\omega^{\prime}\right)$. (See Lemma B.1.) So, if the Voter adopted the neutral news-shifted threshold as his benchmark for reelection, then Voter behavior would exactly offset the effect of the disaster. 


\subsection{The Informativeness Effect}

To add the informativeness effect, we begin with the neutral news-shifted function $N$ and allow informativeness to change from $\iota(\omega)$ to $\iota\left(\omega^{\prime}\right)$. This gives the new loglikelihood function $\ell\left(\cdot, \omega^{\prime}\right)$. Figure 5 illustrates this change in $\iota(\cdot)$ for two cases, one where disasters amplify the effect of type and another where disasters mute the effect of type. In each, the function $\ell\left(\cdot, \omega^{\prime}\right)$ intersects the neutral news-shifted function $N$ at the neutral news outcome $\nu\left(\omega^{\prime}\right)$. This is because the functions $\ell\left(\cdot, \omega^{\prime}\right)$ and $N$ differ only in informativeness; as such, the functions cannot differ at the neutral news outcome. Moreover, in each case, the change in informativeness rotates the likelihood function around the neutral news outcome $\nu\left(\omega^{\prime}\right)$. But, the nature of the rotation depends on whether disasters amplify or mute the effect of type.

[Figure 5 about here.]

Focus on the case where disasters amplify the effect of type (Figure 5a). In that case, the increase in disaster intensity corresponds to an increase in informativeness. Consider a good news outcome $g>\nu\left(\omega^{\prime}\right)$. After observing $g$, the Voter's posterior probability that the Incumbent is a good type increases relative to his prior. By Lemma A.1, when informativeness increases, this good news becomes better news - that is, the Voter's posterior moves even further from his prior. As the analysis in Section 2.3 highlights, a greater increase in the Voter's posterior must be the consequence of a larger value of the loglikelihood ratio. Hence, for any $g>\nu\left(\omega^{\prime}\right), \ell\left(g, \omega^{\prime}\right)$ is greater than $N(g)$. An analogous argument applies to a bad news outcome, $g<\nu\left(\omega^{\prime}\right)$. Since a bad news outcome is worse news when informativeness increases, for any $g<\nu\left(\omega^{\prime}\right), \ell\left(g, \omega^{\prime}\right)$ is less than $N(g)$. Putting these facts together, an increase in informativeness corresponds to a steepening of the graph of the loglikelihood ratio. An analogous argument applies to the case where disasters mute the effect of type (Figure 5b). In that case, an increase in disaster intensity decreases informativeness and, thereby, flattens the graph of the loglikelihood ratio.

Understanding this rotation of the loglikelihood ratio is important for understanding the impact of informativeness on the Voter's reelection threshold. This impact is reflected in the relationship between the neutral news-shifted threshold $n$ and the Voter's new reelection threshold $\hat{g}\left(\omega^{\prime}\right)$. Focus on the case where the Incumbent is ahead, i.e., $\beta\left(\pi_{I}, \pi_{C}\right)<0$. In this case, if disasters amplify the effect of type, then $\hat{g}\left(\omega^{\prime}\right)>n$ and, if disasters mute the effect of type, then $\hat{g}\left(\omega^{\prime}\right)<n$. Put differently, if disasters amplify the effect of type, informativeness increases the reelection threshold and, if disasters mute the effect of type, informativeness decreases the reelection threshold.

To understand why this is the case, assume that disasters amplify the effect of type - so an increase in disaster intensity corresponds to an increase in informativeness. Because the Incumbent is ahead, the neutral news-shifted threshold $n$ is less than the neutral news outcome $\nu\left(\omega^{\prime}\right) .{ }^{8}$ Put differently, because the Incumbent is ahead, the neutral news-shifted threshold $n$ is a bad news

\footnotetext{
${ }^{8}$ Recall, $n$ solves $N(n)=\beta\left(\pi_{I}, \pi_{C}\right)$ and $\nu\left(\omega^{\prime}\right)$ solves $N\left(\nu\left(\omega^{\prime}\right)\right)=\ell\left(\nu\left(\omega^{\prime}\right), \omega^{\prime}\right)=0$. When the Incumbent is ahead $\beta\left(\pi_{I}, \pi_{C}\right)<0$, from which it follows that $n<\nu\left(\omega^{\prime}\right)$.
} 
outcome. Recall, an increase in informativeness makes bad news worse. So, increasing informativeness lowers the Voter's expectation of the Incumbent's type at the neutral news-shifted threshold $n$. Hence, at the neutral news-shifted threshold $n$, the Voter strictly prefers the Challenger to the Incumbent. This is why, in Figure $5 \mathrm{a}, \ell\left(n, \omega^{\prime}\right)<\beta\left(\pi_{I}, \pi_{C}\right)$. This means that $n$ cannot be the Voter's new reelection threshold since, at the Voter's reelection threshold $\hat{g}\left(\omega^{\prime}\right)$, the Voter is indifferent between the Incumbent and the Challenger. To restore indifference, the Voter must use a higher benchmark for reelection. Formally, since $\ell\left(\hat{g}\left(\omega^{\prime}\right), \omega^{\prime}\right)=\beta\left(\pi_{I}, \pi_{C}\right)$, it follows from the MLRP that $\hat{g}\left(\omega^{\prime}\right)>n$.

By contrast, if the governance outcome becomes less informative - as it does when disasters mute the effect of type - this bad news is tempered and so the Voter strictly prefers the Incumbent. Hence, the Voter shifts to a lower benchmark for reelection.

\subsection{The Overall Effect}

Above, we increased the disaster intensity and saw that there are two effects on the Voter's reelection threshold. First, the neutral news effect lowers the reelection threshold. Second, the informativeness effect can either increase or decrease the reelection threshold: When the Incumbent is ahead and the disaster amplifies the effect of type, it increases the reelection threshold. When the Incumbent is ahead and the disaster mutes the effect of type, it decreases the reelection threshold.

Figure 5 depicts the case where the Incumbent is ahead. If disaster amplifies the effect of type, the neutral news effect and informativeness effect work in opposite directions - the former lowers the Voter's benchmark for reelection and the latter increases it. The overall effect is that the Voter's new threshold $\hat{g}\left(\omega^{\prime}\right)$ is greater than the neutral news-shifted threshold $n$. Since the neutral news-shifted threshold exactly offsets the effect of disaster, this implies that rational Voter behavior less than offsets the effect of a disaster. If, instead, disaster mutes the effect of type, the neutral news and the informativeness effects work in the same direction. Consequently, rational Voter behavior more than offsets the effect of disasters.

The conclusions reverse when the Incumbent is behind. The neutral news effect still decreases the Voter's threshold for reelection-i.e., $n<\hat{g}(\omega)$. But, when the Incumbent is behind, the neutral news-shifted threshold $n$ is a good news outcome (relative to $\nu\left(\omega^{\prime}\right)$ ). Thus, the implications for the informativeness effect reverse: An increase in informativeness makes good news even better news. Consequently, at the neutral news-shifted threshold $n$, an increase in informativeness makes it more likely that the Incumbent is a good type and this further lowers the Voter's threshold for reelection. So, in that case, Voter behavior more than offsets the effect of the disaster. By contrast, a decrease in informativeness tempers good news. Consequently, at the neutral news-shifted threshold $n$, a decrease in informativeness makes it less likely that the Incumbent is a good type and this raises the Voter's threshold for reelection. So, in that case, Voter behavior less than offsets the effect of the disaster.

Proposition 3.2. Fix $\omega^{\prime}>\omega$. 
(i) Suppose the Incumbent is ahead. Voter behavior less than offsets the effect of disaster if and only if disasters amplify the effect of type at $\left(\omega, \omega^{\prime}\right)$. Voter behavior more than offsets the effect of disaster if and only if disasters mute the effect of type.

(ii) Suppose the Incumbent is behind. Voter behavior more than offsets the effect of disaster if and only if isasters amplify the effect of type. Voter behavior less than offsets the effect of disaster if and only if disasters mute the effect of type.

Proposition 3.2 implies Proposition 3.1: If disasters amplify (respectively, mute) the effect of type at $\left(\omega, \omega^{\prime}\right)$, then Voter behavior exactly offsets the effect of disaster if and only if $\pi_{I}=\pi_{C}$. Thus, contrary to the message taken from the additive model, it cannot be presumed that rational Voter behavior exactly offsets the effect of disaster.

[Figure 6 about here.]

That the neutral news and informativeness effects can pull in different directions creates the possibility of counterintuitive Voter behavior. In particular, the informativeness effect can dominate the neutral news effect. And that means that a more intense disaster can lead the Voter to use a more stringent reelection threshold. Figure 6 illustrates this point, when disasters amplify the effect of type and the Incumbent is ahead. (See Appendix B.1 for an example.) An analogous example can be provided when disasters mute the effect of type and the Incumbent is behind.

\section{Electoral Fortunes}

We can now investigate how a change in disaster intensity effects the Incumbent's electoral fortunes. We will see that, as with Voter behavior, Incumbent electoral fortunes are typically affected by disaster intensity.

For a given disaster intensity $\omega$, the probability of reelection is determined by two factors: the Voter's reelection threshold $\hat{g}(\omega)$ and the distribution of governance outcomes. This distribution (Equation (7)) can be rewritten as

$$
\Gamma(g ; \omega)=\pi_{I} \Phi(g-\nu(\omega)-\iota(\omega))+\left(1-\pi_{I}\right) \Phi(g-\nu(\omega)+\iota(\omega))
$$

So, when the disaster intensity is $\omega$, the probability that the Incumbent is reelected is $1-\Gamma(\hat{g}(\omega) ; \omega)$.

Changes to disaster intensity affect the probability of reelection via both channels: the Voter's reelection rule and the distribution of governance outcomes. Section 3 explored the impact on the Voter's reelection rule. We now focus on the impact on the distribution of governance outcomes. We will see that disaster intensity affects the distribution of governance outcomes through both a neutral news channel and an informativeness channel. Proposition 4.1 then puts all the effects-on behavior and the distribution of outcomes - together. 


\subsection{The Neutral News Effect}

Suppose that disaster intensity increases from $\omega$ to $\omega^{\prime}$. Again, consider a thought experiment in which the Voter ignores the change in informativeness - holding it fixed at $\iota(\omega)$ - and instead simply filters out the effect of a disaster on the likelihood of observing any given governance outcome. In this case, we consider the neutral news-shifted CDF of governance outcomes:

$$
\mathcal{N}(g)=\pi_{I} \Phi\left(g-\nu\left(\omega^{\prime}\right)-\iota(\omega)\right)+\left(1-\pi_{I}\right) \Phi\left(g-\nu\left(\omega^{\prime}\right)+\iota(\omega)\right)
$$

(This distribution, again, depends on both $\omega$ and $\omega^{\prime}$.) Notice that, for any $g, \Gamma(g ; \omega)<\mathcal{N}(g) .{ }^{9}$ That is, the distribution of outcomes gets worse when disaster intensity increases. (Formally, $\Gamma(\cdot, \omega)$ firstorder stochastically dominates $\mathcal{N}(\cdot)$.) Because, in this thought experiment, the Voter ignores the informativeness effect, the Voter adopts the neutral news-shifted threshold $n=\hat{g}(\omega)-\nu(\omega)+\nu\left(\omega^{\prime}\right)$. (The equality holds because the neutral news-shifted threshold exactly offsets the effect of the disaster.) Overall, these two changes - in the distribution of outcomes and the reelection ruleleave the probability of reelection unchanged. That is, $1-\mathcal{N}(n)=1-\Gamma(\hat{g}(\omega) ; \omega)$.

Notice that the analysis of the neutral news effect corresponds exactly to the additive model. There, changing disaster intensity leaves informativeness unchanged. So the new distribution of governance outcomes, $\Gamma\left(g ; \omega^{\prime}\right)$, corresponds exactly to the distribution $\mathcal{N}$. Moreover, as we have seen, in that case, the Voter's actual new reelection threshold $\hat{g}\left(\omega^{\prime}\right)$ exactly offsets the effect of disaster (i.e., $\hat{g}\left(\omega^{\prime}\right)=n$ ). Thus, $1-\mathcal{N}(n)=1-\Gamma\left(\hat{g}\left(\omega^{\prime}\right) ; \omega^{\prime}\right)$.

When changing disaster intensity changes informativeness, these two properties no longer hold: The new actual distribution $\Gamma\left(\cdot, \omega^{\prime}\right)$ is typically different from the neutral news-shifted distribution $\mathcal{N}$ and the new reelection threshold $\hat{g}\left(\omega^{\prime}\right)$ typically does not exactly offset the effect of the disaster.

\subsection{The Informativeness Effect}

To add the informativeness effect, begin with the hypothetical neutral news-shifted distribution $\mathcal{N}$ and change informativeness from $\iota(\omega)$ to $\iota\left(\omega^{\prime}\right)$; this leads to the new distribution $\Gamma\left(\cdot ; \omega^{\prime}\right)$. Figure 7 illustrates this. The new distribution is a rotation of $\mathcal{N}$ around some point, labeled $r$. That is, $\mathcal{N}(r)=\Gamma\left(r, \omega^{\prime}\right)$.) We refer to $r$ as the rotation point. (The rotation point depends on $\omega$ and $\omega^{\prime}$, since $\mathcal{N}$ does.)

The nature of the rotation depends on whether disaster intensity increases or decreases informativeness. In Figure 7a disasters amplify the effect of type and so informativeness increases. In that case, the new true distribution lies above the neutral news-shifted distribution when the governance outcome $g$ is below the rotation point $r$; that is, if $r>g$, then $\Gamma\left(g, \omega^{\prime}\right)>\mathcal{N}(g)$. In Figure $7 \mathrm{~b}$ disasters mute the effect of type and so informativeness decreases. In that case, the new true distribution lies below the neutral news-shifted distribution when the governance outcome $g$ is below the rotation point $r$; that is, if $r>g$, then $\mathcal{N}(g)>\Gamma\left(g, \omega^{\prime}\right)$. The situation is reversed for

\footnotetext{
${ }^{9}$ Recall, $\nu\left(\omega^{\prime}\right)<\nu(\omega)$.
} 
governance outcomes above the rotation point $r .^{10}$

[Figure 7 about here.]

This change in informativeness systematically changes the likelihood of "tail events," i.e., the likelihood that the outcome $g$ is less than (resp. more than) $g_{*}$ for any $g_{*}<r$ (resp. $g_{*}>r$ ). Refer to Figure $7 \mathrm{a}$, where disasters amplify the effect of type and so informativeness increases. There, the likelihood of these tail events is higher under the new distribution $\Gamma\left(\cdot, \omega^{\prime}\right)$ than under the neutral news-shifted distribution $\mathcal{N}(\cdot)$. (For $g_{*}<r, \Gamma\left(g_{*}, \omega^{\prime}\right)>\mathcal{N}\left(g_{*}\right)$; for $g_{*}>r, 1-\Gamma\left(g_{*}, \omega^{\prime}\right)>1-\mathcal{N}\left(g_{*}\right)$.) Hence, an increase in disaster intensity makes both very bad and very good governance outcomes more likely. Analogously, when disasters mute the effect of type, informativeness decreases and, so, tail events become less likely. ${ }^{11}$

[Figure 8 about here.]

The change in the distribution of outcomes has a direct effect on the probability of reelection. That is, it would change the probability of reelection even if the Voter were to adopt a reelection threshold that exactly offsets the effect of disaster. To see this, refer to Figure 8, which depicts the case where disasters amplify the effect of type. There, the neutral news-shifted threshold $n$ is below the rotation point $r$. Thus, the change in the distribution of outcomes results in a lower probability of reelection, i.e., $1-\Gamma\left(n ; \omega^{\prime}\right)<1-\mathcal{N}(n)=1-\Gamma(\hat{g}(\omega) ; \omega)$. If, instead, the neutral news-shifted threshold $n$ were above the rotation point $r$, the change in the distribution of outcomes would result in a higher probability of reelection, i.e., $1-\Gamma\left(n ; \omega^{\prime}\right)>1-\mathcal{N}(n)=1-\Gamma(\hat{g}(\omega) ; \omega)$.

This raises the question: When does the neutral news-shifted threshold $n$ lie above or below the rotation point $r$ ? The answer depends on whether disasters amplify versus mute the effect of type and on the priors $\pi_{I}$ and $\pi_{C}$. (Lemmata C.11-C.12-C.13 in the Appendix provide a complete analysis.) To understand the role of $\pi_{C}$, consider the extreme case where the Challenger is sufficiently weak (that is, where $\pi_{C}$ is sufficiently small). In that case, the Voter retains the Incumbent at low governance outcomes. Thus, if the Challenger is sufficiently weak, the neutral news-shifted threshold $n$ must be low and, in particular, lower than the rotation point $r .{ }^{12}$ Consequently, if the Challenger is sufficiently weak, an increase (respectively, decrease) in informativeness would decrease (respectively, increase) the likelihood that the Incumbent wins the election and, thereby, be detrimental (respectively, beneficial) to the Incumbent. Likewise, if the Challenger is sufficiently strong, the neutral news-shifted threshold $n$ lies above the rotation point $r$. Consequently, if the Challenger is sufficiently strong, an increase (respectively, decrease) in informativeness would increase (respectively, decrease) the likelihood that the Incumbent wins the election and, thereby, be beneficial (respectively, detrimental) to the Incumbent.

\footnotetext{
${ }^{10}$ These properties follow from log-concavity of $\phi$.

${ }^{11}$ Note, $r$ may not equal $1 / 2$, since the shift in probability mass need not be symmetric.

${ }^{12}$ Note, the rotation point does not depend on the $\pi_{C}$. Moreover, by the MLRP and unboundedness of the likelihood ratio, $N(\cdot)$ is strictly increasing in $g$ and has range $(-\infty, 1)$. Since $N(n)=\beta\left(\pi_{I}, \pi_{C}\right)$, we can choose $\pi_{C}$ sufficiently small so that $n<r$. (The choice of $\pi_{C}$ sufficiently small will depend on the model parameters.)
} 
In sum, when disasters amplify the effect of type, an increase in disaster intensity shifts probability mass towards the tails of the distribution. This is bad for the Incumbent when the Challenger is very likely to be a low type and good for the Incumbent when the Challenger is very likely to be a high type. By contrast, when disasters mute the effect of type, an increase in disaster intensity moves probability mass away from the tails of the distribution. This is good for the Incumbent when the Challenger is very likely to be a low type and bad for the Incumbent when the Challenger is very likely to be a high type.

\subsection{The Overall Effect}

The analysis above focused on the direct effect of disaster intensity on reelection probability. This is captured by the change in distribution of governance outcomes and the relationship between the neutral news-shifted threshold $n$ and the rotation point $r$. But there is a second, indirect effect: A change in disaster intensity also changes the Voter's reelection threshold. This is captured by the relationship between the Voter's new reelection threshold $\hat{g}\left(\omega^{\prime}\right)$ and the neutral news-shifted threshold $n$. As we saw in Section 3, the Voter's reelection threshold does not exactly offset the effect of disaster and, so, $\hat{g}\left(\omega^{\prime}\right) \neq n$.

[Figure 9 about here.]

For an illustration, suppose that disasters amplify the effect of type and the rotation point $r$ is greater than the neutral news-shifted threshold $n$. Refer to Figure 8. In this case, the direct effect causes the probability of reelection to fall. In this figure, Voter behavior less than offsets the effect of disaster (i.e., $\hat{g}\left(\omega^{\prime}\right)>n$ ) and so the indirect effect also causes the probability of reelection to fall. ${ }^{13}$ Figure 9 instead depicts cases where Voter behavior more than offsets the effect of disaster (i.e., $\left.n>\hat{g}\left(\omega^{\prime}\right)\right)$. In those cases, the indirect effect works in the opposite direction. Specifically, it causes the Voter to lower his reelection threshold and, thereby, increases the probability of reelection. In Figure 9a, the direct effect dominates the indirect effect and the overall probability of reelection falls. In Figure 9b, the indirect effect dominates the direct effect and the overall probability of reelection increases.

Table 1 summarizes when Incumbent electoral fortunes will increase versus decrease, based on whether (a) disasters amplify or mute the effect of type, (b) the neutral news-shifted threshold lies above or below the rotation point, and (c) Voter behavior more than or less than offsets the

effect of disasters. In the boxes labeled with [?], the direct and indirect effects compete. There, the Incumbent's electoral fortunes can either increase or decrease depending on parameter values.

[Table 1 about here.]

Table 1 highlights the forces at work, but does not provide a complete understanding of how disaster intensity affects Incumbent electoral fortunes. In particular, the conditions in the table are

\footnotetext{
${ }^{13}$ Formally, $\Gamma\left(\hat{g}\left(\omega^{\prime}\right) ; \omega^{\prime}\right)>\Gamma\left(n ; \omega^{\prime}\right)>\mathcal{N}(n)$.
} 
not at the level of model primitives: They involve two endogenous variables, namely whether the neutral news-shifted threshold lies above or below the rotation point and whether Voter behavior more than or less than offsets the effect of disasters. Using the analysis in Section 3.4, we can re-express these conditions in terms of model primitives.

Toward that end, it will be convenient to introduce some terminology. First, say that the election is doubly symmetric if $\pi_{I}=\pi_{C}=1 / 2$. (A doubly symmetric election is a degenerate case.) Second, given two states $\omega$ and $\omega^{\prime}$, say $\omega^{\prime}$ is more informative than $\omega$ if either (i) $\omega^{\prime}>\omega$ and disasters amplify the effect of type, or (ii) $\omega>\omega^{\prime}$ and disasters mute the effect of type.

Proposition 4.1. Suppose the election is not doubly symmetric and $\omega_{i}$ is more informative than $\omega_{u}$.

(i) If $\pi_{C} \geq \max \left\{\frac{1}{2}, \pi_{I}\right\}$, then the probability of reelection is higher under $\omega_{i}$ than under $\omega_{u}$.

(ii) If $\min \left\{\frac{1}{2}, \pi_{I}\right\} \geq \pi_{C}$, then the probability of reelection is higher under $\omega_{u}$ than under $\omega_{i}$.

Proposition 4.1 covers both the case when disasters amplify the effect of type and when disasters mute the effect of type. Fix $\omega^{\prime}>\omega$. If disasters amplify the effect of type, then $\omega^{\prime} \equiv \omega_{i}$ is more informative than $\omega \equiv \omega_{u}$. If disasters mute the effect of type, then $\omega \equiv \omega_{i}$ is more informative than $\omega^{\prime} \equiv \omega_{u}$.

[Figure 10 about here.]

Figure 10 illustrates the proposition, focusing on an increase disaster intensity. For any given pair $\left(\pi_{I}, \pi_{C}\right)$, it illustrates whether Incumbent's electoral fortunes increase versus decrease in response to this increase in disaster intensity. If disasters amplify the effect of type, more intense disasters increase informativeness. So, in that case, the shaded region corresponds to the pairs $\left(\pi_{I}, \pi_{C}\right)$ for which the reelection probability increases and the non-shaded region corresponds to the pairs for which the reelection probability decreases. If disasters mute the effect of type, more intense disasters reduce informativeness. So, in that case, the shaded region corresponds to the pairs $\left(\pi_{I}, \pi_{C}\right)$ for which the reelection probability decreases and the non-shaded region corresponds to the pairs for which the reelection probability increases. The sole exception is when $\left(\pi_{I}, \pi_{C}\right)=\left(\frac{1}{2}, \frac{1}{2}\right)$. In that case, the neutral news outcome $n$ corresponds exactly to the rotation point $r$ and the Voter exactly offsets the effect of disaster; so that case acts as the additive model-Incumbent electoral fortunes are not affected by disaster intensity.

\section{Conclusion}

In their seminal paper, Achen and Bartels (2004, pp.7-8) write, "To the extent that voters engage in sophisticated attributions of responsibility they should be entirely unresponsive to natural disasters, at least on average; to the extent that they engage in blind retrospection, they should exhibit 'systematic attribution errors'." This claim is emblematic of a large empirical literature, rooted in 
a simple argument: Because natural disasters are outside the control of incumbents, their electoral fortunes will suffer after a natural disaster only if voters are irrational.

We suggest that this interpretation is not warranted, or is at least premature. In a canonical model of voter learning, in all but knife-edged cases, rational voter behavior implies that disastersindeed, any shocks outside the control of policy makers - will affect incumbent electoral fortunes. As such, identifying the impact of natural disasters on incumbent electoral fortunes is not sufficient to infer voter irrationality.

While our results raise challenges for empirical efforts to assess voter rationality, they also suggest a way forward. With a substantive understanding of how disasters affect the informativeness of governance outcomes, an empirical researcher can identify both the impact on electoral fortunes and the ex ante distributions of quality and use this to identify voter (ir)rationality. In the specific case where the exogenous shock does not affect informativeness, it suffices for the researcher to identify the impact on electoral fortunes. This is the case in Healy et al. (2010) and Fowler and Montagnes (2015), where the shock is college sports losses. ${ }^{14}$

An alternative approach contrasts voter rationality with specific forms of bounded rationality. The growing literature making this comparison in models of electoral accountability has focused on normative questions (Callander and Wilson, 2008; Patty, 2006; Ashworth and Bueno de Mesquita, 2014; Diermeier and Li, 2013; Ortoleva and Snowberg, 2015; Levy and Razin, 2015a,b; Lockwood, 2017). Future work might address positive questions, with an eye toward developing tests of specific forms of bounded rationality.

\footnotetext{
${ }^{14}$ Healy et al. (2010) present evidence that incumbent electoral fortunes do depend on those shocks. Fowler and Montagnes (2015) show that the effect is not systematic.
} 


\section{References}

F Glenn Abney and Larry B Hill. Natural disasters as a political variable: The effect of a hurricane on an urban election. The American Political Science Review, pages 974-981, 1966.

Christopher .H. Achen. Social psychology, demographic variables, and linear regression: Breaking the iron triangle in voting research. Political Behavior, 14(3):195-211, 1992.

Christopher H. Achen and Larry M. Bartels. Blind retrospection: Electoral responses to drought, flu, and shark attacks. http://web.international.ucla.edu/media/files/PERG.Achen.pdf, 2004. Unpublished paper.

Christopher H Achen and Larry M Bartels. Democracy for Realists: Why Elections do not Produce Responsive Government. Princeton University Press, 2016.

Nicholas Almendares and Patrick Le Bihan. Increasing leverage: Judicial review as a democracyenhancing institution. Quarterly Journal of Political Science, 2015. Forthcoming.

Scott Ashworth. Reputational dynamics and political careers. Journal of Law, Economics and Organization, 21(2):441-466, October 2005.

Scott Ashworth. Campaign finance and voter welfare with entrenched incumbents. American Political Science Review, 100(1):55-68, 2006.

Scott Ashworth and Ethan Bueno de Mesquita. Delivering the goods: Legislative particularism in different electoral and institutional settings. Journal of Politics, 68(1):169-179, February 2006.

Scott Ashworth and Ethan Bueno de Mesquita. Electoral selection, strategic challenger entry, and the incumbency advantage. Journal of Politics, 70(04):1006-1025, 2008.

Scott Ashworth and Ethan Bueno de Mesquita. Is voter competence good for voters?: Information, rationality, and democratic performance. American Political Science Review, 108(3):565-587, 2014 .

Scott Ashworth, Ethan Bueno de Mesquita, and Amanda Friedenberg. Accountability and information in elections. American Economic Journal: Microeconomics, 9(2):95-138, 2017.

Jeffrey S. Banks and Rangarajan K. Sundaram. Moral hazard and adverse selection in a model of repeated elections. In William A. Barnett, Melvin J. Hinich, and Norman J. Schfield, editors, Political Economy: Institutions, Information, Competition, and Representation. Cambridge University Press, Cambridge, 1993.

Larry M. Bartels. Messages received: The political impact of media exposure. American Political Science Review, pages 267-285, 1993. 
Michael M. Bechtel and Jens Hainmueller. How lasting is voter gratitude? an analysis of the short-and long-term electoral returns to beneficial policy. American Journal of Political Science, $55(4): 852-868,2011$.

Timothy Besley. Principled Agents?: The Political Economy of Good Governement. Oxford University Press, Oxford, 2006.

Timothy Besley and Robin Burgess. The political economy of government responsiveness: Theory and evidence from india. Quarterly Journal of Economics, 117(4):1415-1451, 2002.

Timothy Besley and Andrea Prat. Handcuffs for the grabbing hand? media capture and government accountability. American Economic Review, 96(3):720-736, 2006.

David Blackwell. The comparison of experiments. In Proceedings, Second Berkeley Symposium on Mathematical Statistics and Probability, pages 93-102. University of California Press, Berkeley, 1951.

Steven Callander and Catherine H. Wilson. Context-dependent voting and political ambiguity. Journal of Public Economics, 92(3):565-581, 2008.

Angus Campbell, Philip E. Converse, Warren E. Miller, and Donald E. Stokes. The American Voter. John Wiley \& Sons, New York, 1960.

Brandice Canes-Wrone, Michael C. Herron, and Kenneth W. Shotts. Leadership and pandering: A theory of executive policymaking. American Journal of Political Science, 45:532-550, 2001.

Jowei Chen. Voter partisanship and the effect of distributive spending on political participation. American Journal of Political Science, 57(1):200-217, 2013.

Stephen Coate. Pareto-improving campaign finance policy. American Economic Review, 94(3): 628-655, June 2004.

Shawn Cole, Andrew Healy, and Eric Werker. Do voters demand responsive governments? evidence from indian disaster relief. Journal of Development Economics, 97(2):167-181, 2012.

Brendan Daley and Erik Snowberg. Even if it is not bribery: The case for campaign finance reform. Journal of Law, Economics, and Organization, 27(2):301-323, August 2011.

Michael X. Delli Carpini and Scott Keeter. What Americans Know About Politics and Why It Matters. Yale University Press, New Haven, 1996.

Daniel Diermeier and Christopher Li. A behavioral theory of electoral control. https://drive . google.com/file/d/OBzx4BWwOGhUQLUVsQXNwZlZLbnc/view, 2013. Northwestern typescript.

Anthony Downs. An Economic Theory of Democracy. New York: Harper and Row, 1957. 
Michael Ebeid and Jonathan Rodden. Economic geography and economic voting: Evidence from the us states. British Journal of Political Science, 36(3):527, 2006.

Andrew C. Eggers. Quality-based explanations of incumbency effects. https://www.dropbox.com/ s/uxz90fnzjx8dxam/close_elections_and_candidate_type_v22_to_distribute.pdf?dl=0, 2015. Unpublished Manuscript.

Ray C. Fair. The effect of economic events on votes for president. The Review of Economics and Statistics, 60(2):159-173, 1978.

James D. Fearon. Electoral accountability and the control of politicians: Selecting good types versus sanctioning poor performance. In Adam Przeworski, Susan Stokes, and Bernard Manin, editors, Democracy, Accountability, and Representation. Cambridge University Press, New York, 1999.

Morris P. Fiorina. Retrospective Voting in American National Elections. Yale University Press, New Haven, 1981.

Anthony Fowler and B. Pablo Montagnes. College football, elections, and false-positive results in observational research. Proceedings of the National Academy of Sciences, 112(45):13800-13804, 2015 .

Justin Fox and Stuart V. Jordan. Delegation and accountability. Journal of Politics, 73(3):831-844, 2011.

Justin Fox and Matthew C. Stephenson. Judicial review as a response to political posturing. American Political Science Review, 105(2):397-414, 2011.

Justin Fox and Matthew C. Stephenson. The welfare effects of minority-protective judicial review. Journal of Theoretical Politics, 27(4):499-521, 2015.

Justin Fox and Richard Van Weelden. Partisanship and the effectiveness of oversight. Journal of Public Economics, 94(9-10):684-697, 2010.

Justin Fox and Richard Van Weelden. Costly transparency. Journal of Public Economics, 96(1-2): 142-150, 2012.

Sean Gailmard and John W. Patty. Preventing prevention. https://www.dropbox.com/s/ zf6ohdnm3uopw72/Accountability-Tech1.pdf?dl=0, 2014. Berkeley typescript.

John T Gasper and Andrew Reeves. Make it rain? retrospection and the attentive electorate in the context of natural disasters. American Journal of Political Science, 55(2):340-355, 2011.

Scott Gehlbach. Electoral institutions and the national provision of local public goods. Quarterly Journal of Political Science, 2(1):5-25, March 2007. 
Alan Gerber and Donald Green. Misperceptions about perceptual bias. Annual review of political science, 2(1):189-210, 1999.

Christian Gollier. The Economics of Risk and Time. MIT Press, Cambridge, 2001.

Sanford C. Gordon, Gregory A. Huber, and Dimitri Landa. Challenger entry and voter learning. American Political Science Review, 101(2):303-320, May 2007.

A. Healy and N. Malhotra. Random events, economic losses, and retrospective voting: Implications for democratic competence. Quarterly Journal of Political Science, 5(2):193-208, 2010.

A.J. Healy, N. Malhotra, and C.H. Mo. Irrelevant events affect voters' evaluations of government performance. Proceedings of the National Academy of Sciences, 107(29):12804-12809, 2010.

Gregory A. Huber, Seth J. Hill, and Gabriel S. Lenz. Sources of bias in retrospective decision making: Experimental evidence on voters' limitations in controlling incumbents. American Political Science Review, 106(04):720-741, 2012.

Mark Andreas Kayser and Michael Peress. Benchmarking across borders: Electoral accountability and the necessity of comparison. American Political Science Review, 106(03):661-684, 2012.

V.O. Key. The Responsible Electorate: Rationality in Presidential Voting, 1936-1960. Belknap Press of Harvard University Press, Cambridge, 1966.

Donald R. Kinder and David O. Sears. Public opinion and political action. The Handbook of Social Psychology, 2(3):659-661, 1985.

Andrew Leigh. Does the world economy swing national elections? Oxford Bulletin of Economics and Statistics, 71(2):163-181, 2009.

Gilat Levy and Ronny Razin. Correlation neglect, voting behavior, and information aggregation. American Economic Review, 105(4):1634-45, 2015a.

Gilat Levy and Ronny Razin. Does polarization of opinion lead to polarization of platforms?: The case of correlation neglect. Quarterly Journal of Political Science, 10(3):321-355, 2015b.

Ben Lockwood. Confirmation bias and electoral accountability. Quarterly Journal of Political Science, 11(4):471-501, 2017.

Susanne Lohmann. An informational rationale for the power of special interests. American Political Science Review, 92(4):809-827, 1998.

Arthur Lupia. Shortcuts versus encyclopedias: Information and voting behavior in california insurance reform elections. American Political Science Review, pages 63-76, 1994.

Eric Maskin and Jean Tirole. The politician and the judge: Accountability in government. American Economic Review, 94(4):1034-1054, 2004. 
Roger B. Myerson. Federalism and incentives for success of democracy. Quarterly Journal of Political Science, 1(1):3-23, January 2006.

Pietro Ortoleva and Erik Snowberg. Overconfidence in political behavior. American Economic Review, 105(2):504-35, 2015.

John W Patty. Loss aversion, presidential responsibility, and midterm congressional elections. Electoral Studies, 25(2):227-247, 2006.

Torsten Persson and Guido Tabellini. Political Economics: Explaining Economic Policy. MIT Press, Cambridge, 2000.

Samuel L Popkin. The reasoning voter: Communication and persuasion in presidential campaigns. University of Chicago Press, 1991.

Paul M. Sniderman, Richard A. Brody, and Phillip E. Tetlock. Reasoning and Choice: Explorations in Political Psychology. Cambridge University Press, 1993.

Justin Wolfers. Are voters rational?: Evidence from gubernatorial elections. http://citeseerx . ist.psu.edu/viewdoc/download?doi=10.1.1.10.8311\&rep=rep1\&type=pdf, 2002. Stanford Graduate School of Business Research Paper Series \#1730. 

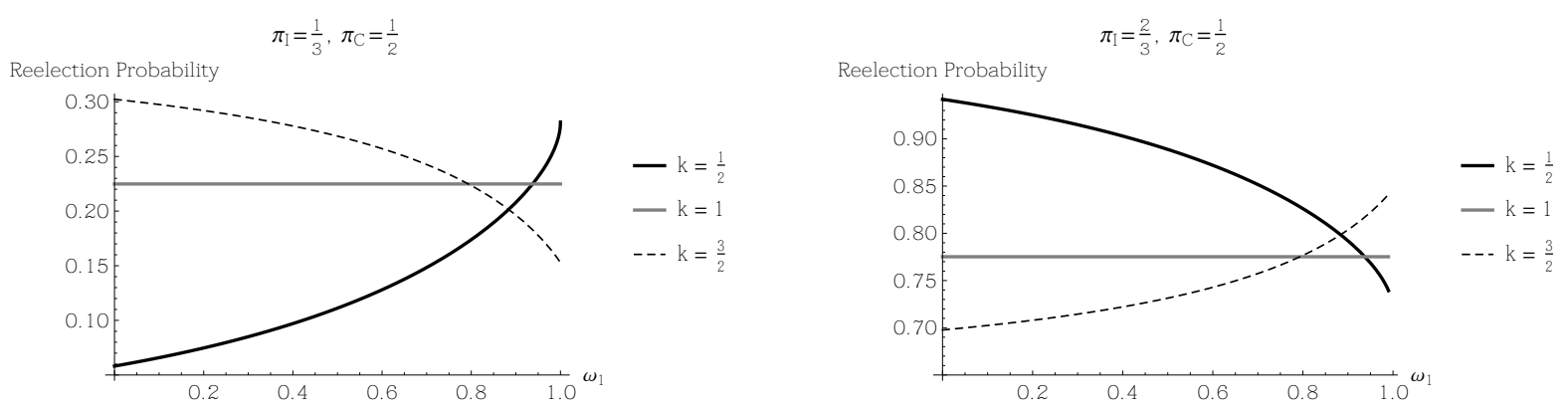

Figure 1. Reelection probability as a function of $\omega_{1}$ for $\underline{\theta}=1$ and $\bar{\theta}=\frac{3}{2}$. 


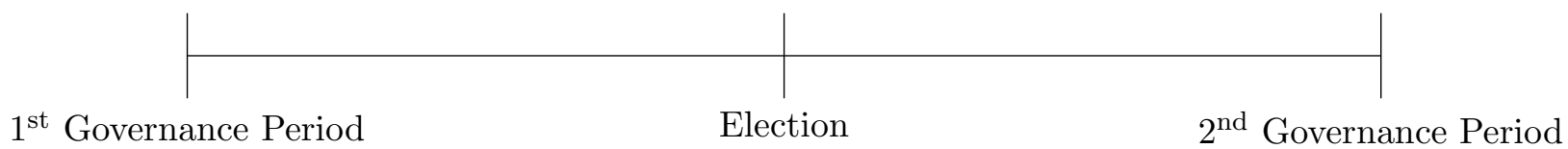

Figure 2. Timeline 


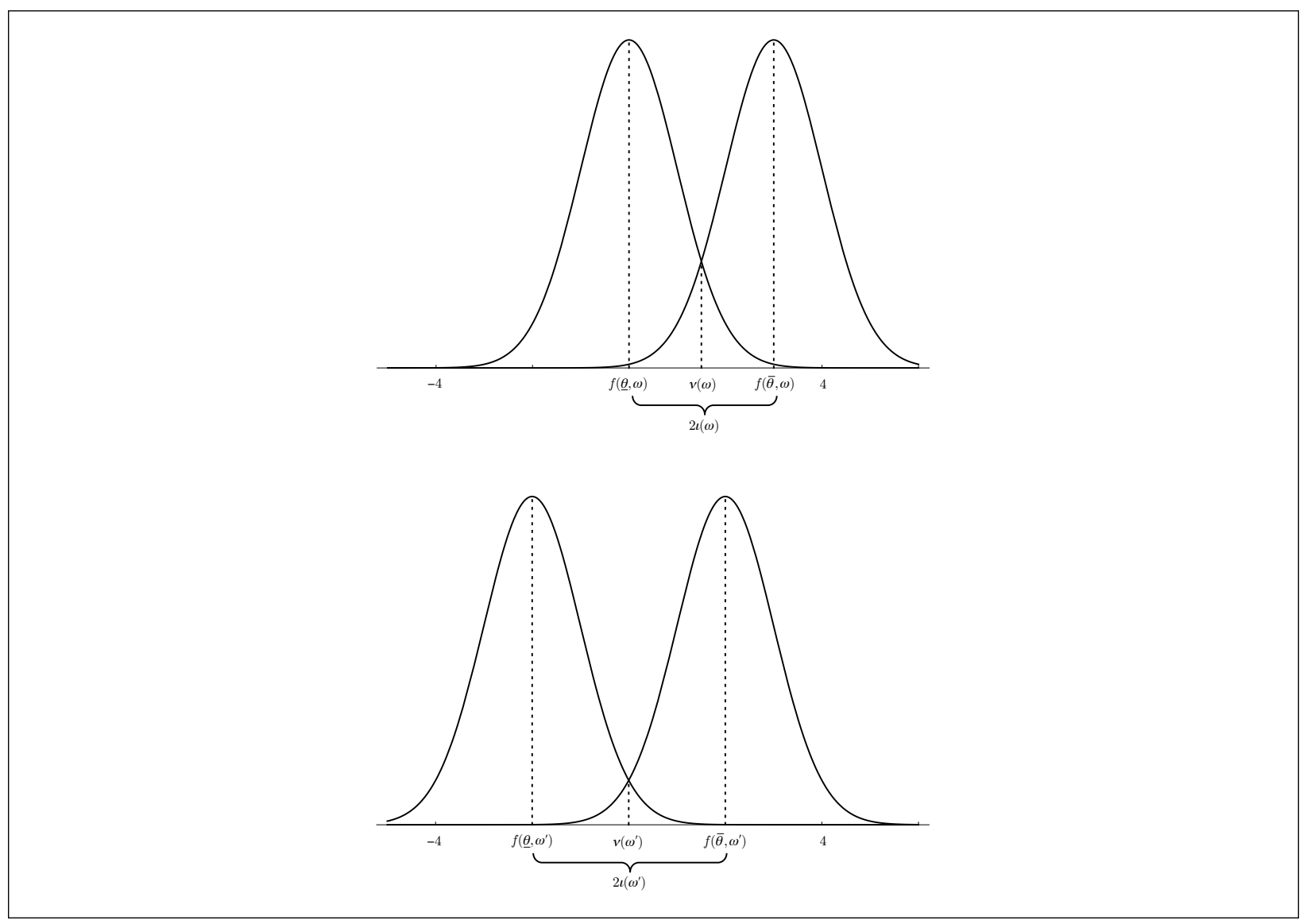

Figure 3. Amplifies: Effect of Increase in Disaster on Conditional Distributions 


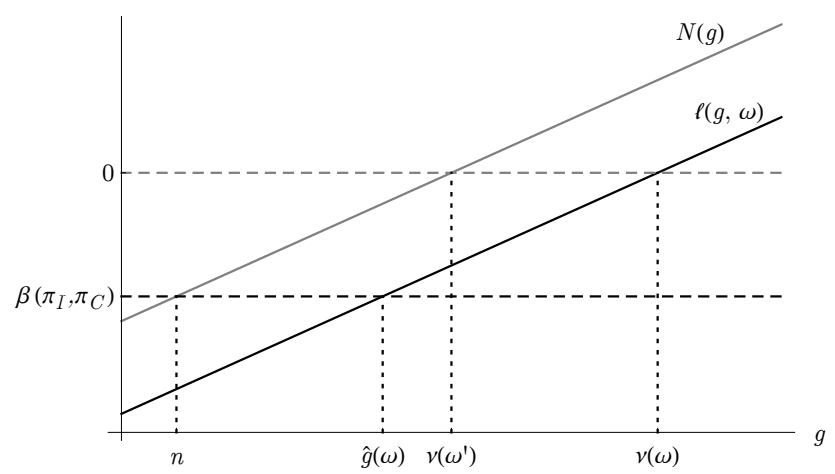

Figure 4. Neutral News Effect 


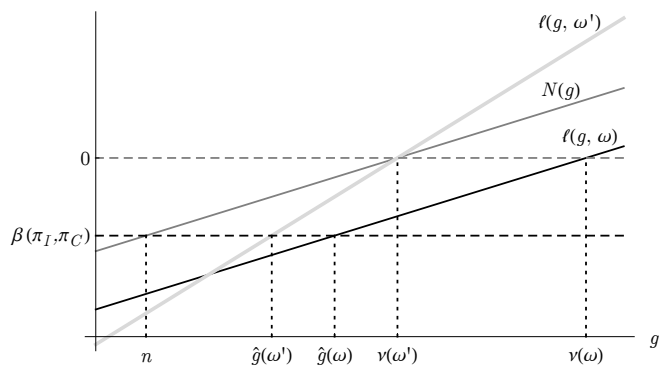

(a) Disasters Amplify the Effect of Type

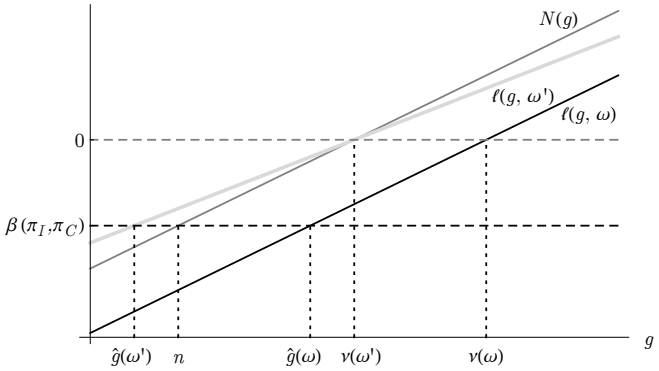

(b) Disasters Mute the Effect of Type

Figure 5. Informativeness Effect 


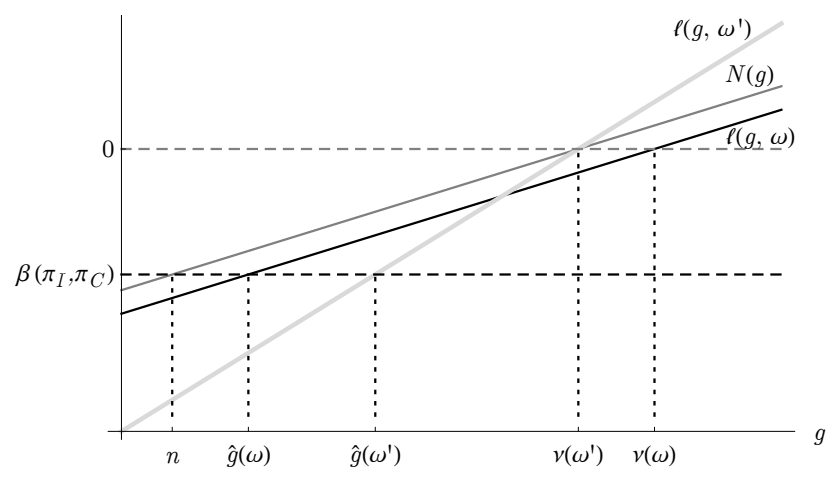

Figure 6. Informational Effect Dominates Neutral News Effect 


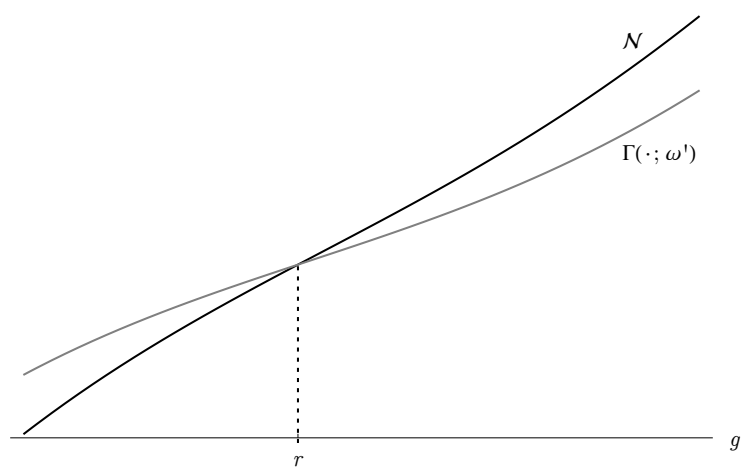

(a) Disasters Amplify the Effect of Type

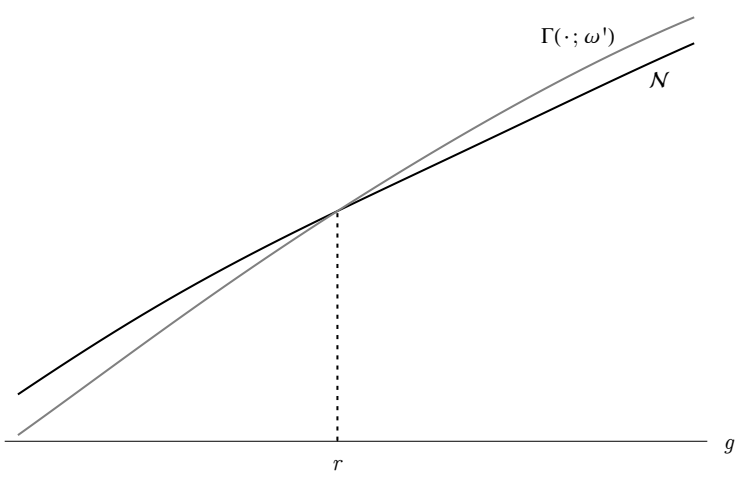

(b) Disasters Mute the Effect of Type

Figure 7. How Informativeness Changes the Distribution of Outcomes 


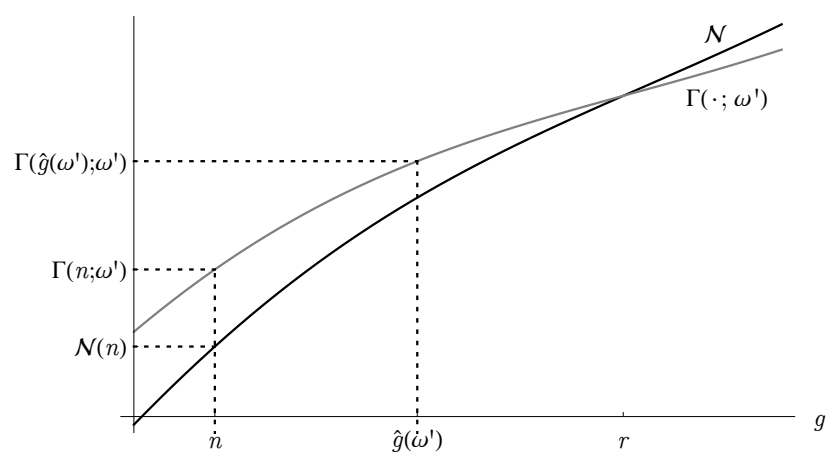

Figure 8. Amplify and $n<\hat{g}\left(\omega^{\prime}\right)<r$ : Probability of Reelection Falls 


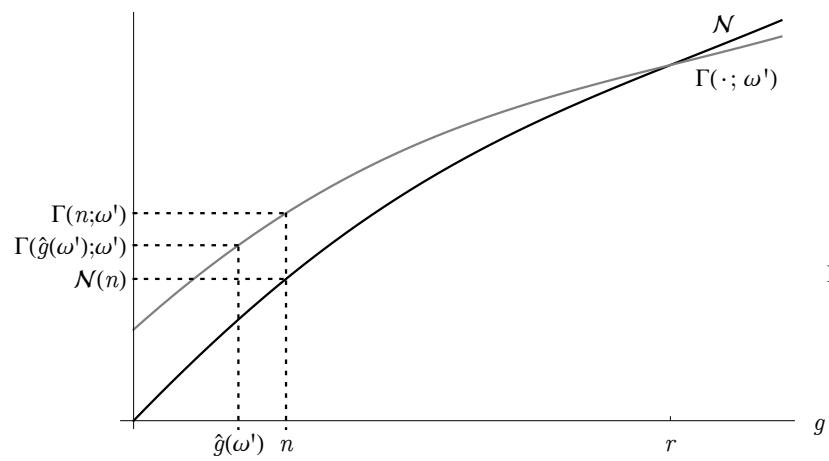

(a) Probability of Reelection Falls

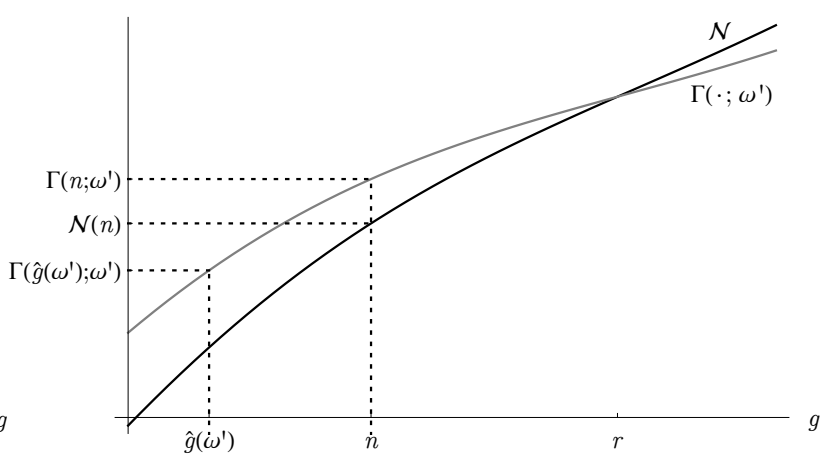

(b) Probability of Reelection Rises

Figure 9. Amplifies and $\hat{g}\left(\omega^{\prime}\right)<n<r$ 


\begin{tabular}{|c|c|c|}
\hline & Amplifies & Mutes \\
\hline$n>r$ & $?$ & Reelec Prob $\downarrow$ \\
\hline$n<r$ & Reelec Prob $\downarrow$ & $?$ \\
\hline
\end{tabular}

Less Than Offsets

\begin{tabular}{c|c|c|}
\multicolumn{1}{c}{} & \multicolumn{1}{c}{ Amplifies } & \multicolumn{1}{c}{ Mutes } \\
\cline { 2 - 3 }$n>r$ & Reelec Prob $\uparrow$ & $?$ \\
\cline { 2 - 3 }$n<r$ & $?$ & Reelec Prob $\uparrow$ \\
\cline { 2 - 3 } & &
\end{tabular}

More Than Offsets

Table 1. Change in Electoral Fortunes 


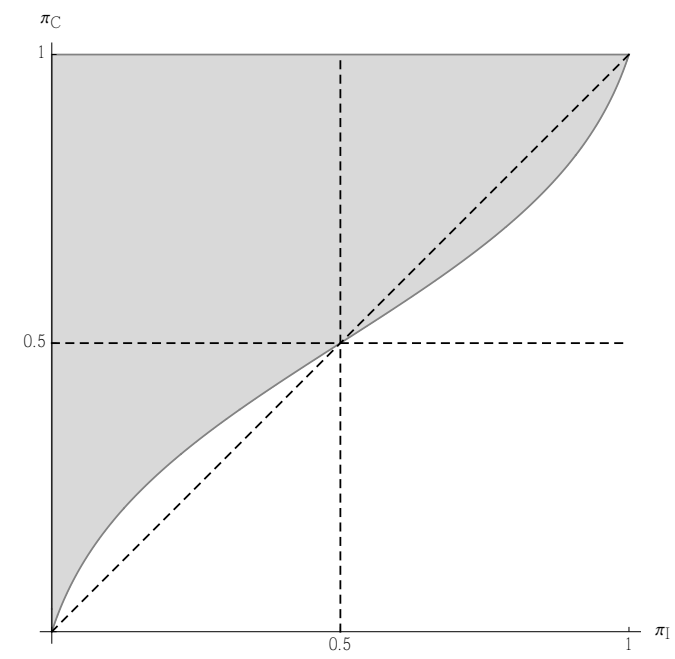

Figure 10. Amplify: Reelection prob. higher for more intense disaster in shaded, lower in unshaded Mute: Reelection prob. lower for more intense disaster in shaded, higher in unshaded 


\section{Learning About Voter Rationality: Supplemental Material (For Online Publication)}




\section{A Preliminary Results}

In this Appendix, we report a technical result that will be useful in the subsequent analysis. This result is Lemma B.2 in Ashworth et al. (2017), so the proof is omitted.

Lemma A.1. Consider a function $\mathcal{L}: \mathbb{R} \times \mathbb{R}_{+} \rightarrow \mathbb{R}_{+}$given by

$$
\mathcal{L}(x, \delta)=\frac{\phi(x-\delta)}{\phi(x+\delta)}
$$

(i) $\mathcal{L}$ is increasing in $\delta$ if $x>0$.

(ii) $\mathcal{L}$ is constant in $\delta$ if $x=0$.

(iii) $\mathcal{L}$ is decreasing in $\delta$ if $x<0$.

\section{B Proofs for Section 3}

Propositions 3.1-3.2 in the main text are a corollary of the following:

Proposition B.1. Fix $\omega^{\prime}>\omega$.

(i) Suppose disasters amplify the effect of type at $\left(\omega, \omega^{\prime}\right)$. Then $\pi_{I} \geq \pi_{C}$ if and only if $\nu(\omega)-$ $\nu\left(\omega^{\prime}\right) \geq \hat{g}(\omega)-\hat{g}\left(\omega^{\prime}\right)$ and $\pi_{C} \geq \pi_{I}$ if and only if $\hat{g}(\omega)-\hat{g}\left(\omega^{\prime}\right) \geq \nu(\omega)-\nu\left(\omega^{\prime}\right)$.

(ii) Suppose disasters neither amplify nor mute the effect of type at $\left(\omega, \omega^{\prime}\right)$. Then, for any $\pi_{I}$ and $\pi_{C}, \nu(\omega)-\nu\left(\omega^{\prime}\right)=\hat{g}(\omega)-\hat{g}\left(\omega^{\prime}\right)$.

(iii) Suppose disasters mute the effect of type at $\left(\omega, \omega^{\prime}\right)$. Then $\pi_{I} \geq \pi_{C}$ if and only if $\hat{g}(\omega)-\hat{g}\left(\omega^{\prime}\right) \geq$ $\nu(\omega)-\nu\left(\omega^{\prime}\right)$ and $\pi_{C} \geq \pi_{I}$ if and only if $\nu(\omega)-\nu\left(\omega^{\prime}\right) \geq \hat{g}(\omega)-\hat{g}\left(\omega^{\prime}\right)$.

Observe that the statement of the proposition has implications for strict inequalities: Suppose that, $\pi_{I}>\pi_{C}$ and disasters amplify the effect of type at $\left(\omega, \omega^{\prime}\right)$. Then we can apply the fact that " $\pi_{I} \geq \pi_{C}$ " and "not $\pi_{C} \geq \pi_{I}$ " to obtain that $\nu(\omega)-\nu\left(\omega^{\prime}\right)>\hat{g}(\omega)-\hat{g}\left(\omega^{\prime}\right)$. Thus, part (i) and (iii) say: Suppose the Incumbent is ahead (i.e., $\pi_{I}>\pi_{C}$ ). Then disasters amplify (resp. mute) the effect of type at $\left(\omega, \omega^{\prime}\right)$ if and only if $\nu(\omega)-\nu\left(\omega^{\prime}\right)>\hat{g}(\omega)-\hat{g}\left(\omega^{\prime}\right)\left(\operatorname{resp} . \hat{g}(\omega)-\hat{g}\left(\omega^{\prime}\right)>\nu(\omega)-\nu\left(\omega^{\prime}\right)\right)$ or if and only if Voter behavior less (resp. more) than offsets the effect of a disaster. And, analogously for the other requirements.

This Proposition follows from two Lemmata. The first formalizes the discussion surrounding Figure 4.

Lemma B.1. Fix $\omega^{\prime}>\omega$.

(i) For each $g, N(g)>\ell(g, \omega)$.

(ii) If $N(n)=\beta\left(\pi_{I}, \pi_{C}\right)$, then $\hat{g}(\omega)-n=\nu(\omega)-\nu\left(\omega^{\prime}\right)$. 
Proof. Observe that, for each $g$, there exists some $g^{\prime}>g$ so that $g=g^{\prime}+\left(\nu\left(\omega^{\prime}\right)-\nu(\omega)\right)$. Since

$$
N(g)=\log \frac{\phi\left(g-\nu\left(\omega^{\prime}\right)-\iota(\omega)\right)}{\phi\left(g-\nu\left(\omega^{\prime}\right)+\iota(\omega)\right)}=\log \frac{\phi\left(g^{\prime}-\nu(\omega)-\iota(\omega)\right)}{\phi\left(g^{\prime}-\nu(\omega)+\iota(\omega)\right)}=\ell\left(g^{\prime}, \omega\right)
$$

and (by the strict MLRP) $\ell\left(g^{\prime}, \omega\right)>\ell(g, \omega)$, it follows that $N(g)>\ell(g, \omega)$.

If $N(n)=\beta\left(\pi_{I}, \pi_{C}\right)$, then

$$
\log \frac{\phi\left(n-\nu\left(\omega^{\prime}\right)-\iota(\omega)\right)}{\phi\left(n-\nu\left(\omega^{\prime}\right)+\iota(\omega)\right)}=\log \frac{\phi(\hat{g}(\omega)-\nu(\omega)-\iota(\omega))}{\phi(\hat{g}(\omega)-\nu(\omega)+\iota(\omega))} .
$$

By the strict MLRP, this implies that $n-\nu\left(\omega^{\prime}\right)=\hat{g}(\omega)-\nu(\omega)$.

The second lemma formalizes the "rotation" effect discussed surrounding Figures 5a, 6, and 5b.

Lemma B.2. Fix $\omega^{\prime}>\omega$.

(i) Suppose disasters amplify the effect of type at $\left(\omega, \omega^{\prime}\right)$. Then $g \geq \nu\left(\omega^{\prime}\right)$ if and only if $\ell\left(g, \omega^{\prime}\right) \geq$ $N(g)$ and $g \leq \nu\left(\omega^{\prime}\right)$ if and only if $\ell\left(g, \omega^{\prime}\right) \leq N(g)$.

(ii) Suppose disasters mute the effect of type at $\left(\omega, \omega^{\prime}\right)$. Then $g \geq \nu\left(\omega^{\prime}\right)$ if and only if $\ell\left(g, \omega^{\prime}\right) \leq$ $N(g)$ and $g \leq \nu\left(\omega^{\prime}\right)$ if and only if $\ell\left(g, \omega^{\prime}\right) \geq N(g)$.

Proof. Immediate from Lemma A.1.

Note, again, that while these statements involve weak inequalities they have implications about strict inequalities. For instance, if $g>\nu\left(\omega^{\prime}\right)$ and disasters amplify the effect of type at $\left(\omega, \omega^{\prime}\right)$ then, using the fact that "not $g \leq \nu\left(\omega^{\prime}\right)$ " it follows that $\ell\left(g, \omega^{\prime}\right)>N(g)$.

Proof of Proposition B.1. We show the result for the case where $\pi_{I} \geq \pi_{C}$ (or, equivalently, $\left.\beta\left(\pi_{I}, \pi_{C}\right) \leq 0\right)$ and disasters amplify the effect of type at $\left(\omega, \omega^{\prime}\right)$. The other cases are analogous.

In this case, we want to show that $\nu(\omega)-\nu\left(\omega^{\prime}\right) \geq \hat{g}(\omega)-\hat{g}\left(\omega^{\prime}\right)$. By Lemma B.1(ii), this is true provided $\hat{g}(\omega)-n \geq \hat{g}(\omega)-\hat{g}\left(\omega^{\prime}\right)$ or, equivalently, provided $\hat{g}\left(\omega^{\prime}\right) \geq n$.

To show this, observe that

$$
\ell\left(\nu\left(\omega^{\prime}\right), \omega^{\prime}\right)=0 \geq \beta\left(\pi_{I}, \pi_{C}\right)=\ell\left(\hat{g}\left(\omega^{\prime}\right), \omega^{\prime}\right)
$$

So, by the MLRP, $\nu\left(\omega^{\prime}\right) \geq \hat{g}\left(\omega^{\prime}\right)$. From this, the fact that disasters amply the effect of type at $\left(\omega, \omega^{\prime}\right)$, and Lemma B.2, $N\left(\hat{g}\left(\omega^{\prime}\right)\right) \geq \ell\left(\hat{g}\left(\omega^{\prime}\right), \omega^{\prime}\right)$. It follows that

$$
N\left(\hat{g}\left(\omega^{\prime}\right)\right) \geq \ell\left(\hat{g}\left(\omega^{\prime}\right), \omega^{\prime}\right)=\beta\left(\pi_{I}, \pi_{C}\right)=N(n)
$$

Since $N$ is increasing, it follows that $\hat{g}\left(\omega^{\prime}\right) \geq n$, as desired. 


\section{B.1 Computational Examples}

Figures 4-6 were drawn based on numerical examples. We now give details on the numerical examples, to illustrate that the effects depicted can indeed arise.

The examples have several features in common: In each, $\phi$ is the pdf of a standard normal distribution: $\phi(x)=\frac{1}{\sqrt{2 \pi}} \exp \left(-x^{2} / 2\right)$. Also, in each $\pi_{C}=\frac{1}{2}, \omega^{\prime}=\frac{1}{2}$, and $\omega^{\prime \prime}=1$. The examples vary in the production function and the choice of $\pi_{I}$. These choices are described in Table 2 .

\begin{tabular}{cccc}
\hline & \multicolumn{3}{c}{ Figure } \\
\cline { 2 - 4 } & $4 \& 5 \mathrm{a}$ & $5 \mathrm{~b}$ & 6 \\
\hline$f(\bar{\theta}, \omega)$ & $1-\omega$ & $4-2 \omega$ & $1-\omega$ \\
$f(\underline{\theta}, \omega)$ & $1-4 \omega$ & $1-\omega$ & $1-2 \omega$ \\
$\pi_{I}$ & $\frac{1}{1+\exp (-2.5)}$ & $\frac{1}{1+\exp (-2.5)}$ & $\frac{1}{1+\exp (-2)}$ \\
\hline
\end{tabular}

Table 2. Parameters for the numerical examples.

We can analytically solve for the Voter's reelection threshold. Using the formula for the normal PDF, $\ell(g, \omega)=2 \iota(\omega)(g-\nu(\omega))$. So we can solve explicitly for $\hat{g}$ :

$$
\hat{g}(\omega)=\frac{\beta\left(\pi_{I}, \pi_{C}\right)}{2 \iota(\omega)}+\nu(\omega)
$$

Figure 6 depicted a situation in which an increase in disaster intensity caused the benchmark for reelection to rise. With this in mind, we will show that $\hat{g}\left(\omega^{\prime \prime}\right)>\hat{g}\left(\omega^{\prime}\right)$. Using the explicit solution for $\hat{g}(\omega)$, and the last column of Table $2, \nu(\omega)=(2-3 \omega) / 2, \iota(\omega)=\omega / 2$, and $\beta\left(\pi_{I}, \pi_{C}\right)=-2$. So,

$$
\hat{g}\left(\omega^{\prime}\right)=-\frac{15}{4}<-\frac{10}{4}=\hat{g}\left(\omega^{\prime \prime}\right)
$$

Thus, as the disaster becomes more intense, the reelection threshold becomes more stringent.

\section{Proofs for Section 4}

Proposition 4.1 in the main text is a corollary of the following results:

Proposition C.1. Fix an election that is not doubly symmetric. Suppose that $\omega^{\prime}>\omega$ and disasters amplify the effect of type.

(i) If $\pi_{C} \geq \max \left\{\frac{1}{2}, \pi_{I}\right\}$, then $1-\Gamma\left(\hat{g}\left(\omega^{\prime}\right) ; \omega^{\prime}\right)>1-\Gamma(\hat{g}(\omega) ; \omega)$.

(ii) If $\min \left\{\frac{1}{2}, \pi_{I}\right\} \geq \pi_{C}$, then $1-\Gamma(\hat{g}(\omega) ; \omega)>1-\Gamma\left(\hat{g}\left(\omega^{\prime}\right) ; \omega^{\prime}\right)$.

Proposition C.2. Fix an election that is not doubly symmetric. Suppose that $\omega^{\prime}>\omega$ and disasters mute the effect of type.

(i) If $\min \left\{\frac{1}{2}, \pi_{I}\right\} \geq \pi_{C}$, then $1-\Gamma\left(\hat{g}\left(\omega^{\prime}\right) ; \omega^{\prime}\right)>1-\Gamma(\hat{g}(\omega) ; \omega)$. 
(ii) If $\pi_{C} \geq \max \left\{\frac{1}{2}, \pi_{I}\right\}$, then $1-\Gamma(\hat{g}(\omega) ; \omega)>1-\Gamma\left(\hat{g}\left(\omega^{\prime}\right) ; \omega^{\prime}\right)$.

We begin by analyzing how the change in informativeness - going form $\mathcal{N}$ to $\Gamma\left(\cdot, \omega^{\prime}\right)$-rotates the distribution of governance outcomes. We then use this fact to conclude whether the reelection probability would increase or decrease, depending on (a) where $n$ lies relative to the rotation point and (b) whether the incumbent is ahead versus behind. Finally, we conclude by providing parameters of the model that pin down where $n$ lies relative to the rotation point.

The Effect of Informativeness: Rotating the Distribution $\mathcal{N}$ Write

$$
\mathcal{G}(x ; \delta)=\pi_{I} \Phi(x-\delta)+\left(1-\pi_{I}\right) \Phi(x+\delta) .
$$

Observe that

$$
\frac{\partial \mathcal{G}}{\partial \delta}(x ; \delta)=-\pi_{I} \phi(x-\delta)+\left(1-\pi_{I}\right) \phi(x+\delta) .
$$

Notice that $\mathcal{N}(g)=\mathcal{G}\left(g-\nu\left(\omega^{\prime}\right), \iota(\omega)\right)$ and $\Gamma\left(g ; \omega^{\prime}\right)=\mathcal{G}\left(g-\nu\left(\omega^{\prime}\right), \iota\left(\omega^{\prime}\right)\right)$. Thus, we will be interested in how the function $\mathcal{G}(x ; \delta)$ responds to changes in $\delta$.

Lemma C.1. Fix $\delta^{\prime} \neq \delta$. There is exactly one $\bar{x}$ such that $\mathcal{G}\left(\bar{x} ; \delta^{\prime}\right)=\mathcal{G}(\bar{x} ; \delta)$. Moreover:

(i) For $\delta^{\prime}>\delta$ : If $\bar{x}>x$ then $\mathcal{G}\left(x ; \delta^{\prime}\right)>\mathcal{G}(x ; \delta)$ and if $x>\bar{x}$ then $\mathcal{G}(x ; \delta)>\mathcal{G}\left(x ; \delta^{\prime}\right)$.

(ii) For $\delta>\delta^{\prime}$ : If $\bar{x}>x$ then $\mathcal{G}(x ; \delta)>\mathcal{G}\left(x ; \delta^{\prime}\right)$ and if $x>\bar{x}$ then $\mathcal{G}\left(x ; \delta^{\prime}\right)>\mathcal{G}(x ; \delta)$.

The level $\bar{x}$ that solves $\mathcal{G}\left(\bar{x} ; \delta^{\prime}\right)=\mathcal{G}(\bar{x} ; \delta)$ will typically depend on both $\delta$ and $\delta^{\prime}$.

To show Lemma C.1, it will be useful to fix $\delta^{\prime} \neq \delta$ and define auxiliary functions $\Delta(\cdot): \mathbb{R} \rightarrow \mathbb{R}$ and $\Xi(\cdot): \mathbb{R} \rightarrow \mathbb{R}$ so that

$$
\begin{aligned}
\Delta(x) & =\mathcal{G}\left(x ; \delta^{\prime}\right)-\mathcal{G}(x ; \delta) \\
& =\pi_{I}\left[\Phi\left(x-\delta^{\prime}\right)-\Phi(x-\delta)\right]+\left(1-\pi_{I}\right)\left[\Phi\left(x+\delta^{\prime}\right)-\Phi(x+\delta)\right]
\end{aligned}
$$

and

$$
\Xi(x)=-\frac{\Phi\left(x-\delta^{\prime}\right)-\Phi(x-\delta)}{\Phi\left(x+\delta^{\prime}\right)-\Phi(x+\delta)} .
$$

We begin with the following observation, which follows directly from calculations:

Lemma C.2. Suppose $\delta^{\prime}>\delta$.

(i) $\Delta(x) \geq 0$ if and only if $\frac{1-\pi_{I}}{\pi_{I}} \geq \Xi(x)$.

(ii) $\Delta(x) \leq 0$ if and only if $\frac{1-\pi_{I}}{\pi_{I}} \leq \Xi(x)$.

Lemma C.3. Suppose $\delta>\delta^{\prime}$. 
(i) $\Delta(x) \geq 0$ if and only if $\frac{1-\pi_{I}}{\pi_{I}} \leq \Xi(x)$.

(ii) $\Delta(x) \leq 0$ if and only if $\frac{1-\pi_{I}}{\pi_{I}} \geq \Xi(x)$.

\section{Lemma C.4.}

(i) If $\delta^{\prime}>\delta$, the function $\Xi(\cdot)$ is strictly increasing in $x$.

(ii) If $\delta>\delta^{\prime}$, the function $\Xi(\cdot)$ is strictly decreasing in $x$.

Proof. Observe that

$\Xi^{\prime}(x)=-\frac{\left(\phi\left(x-\delta^{\prime}\right)-\phi(x-\delta)\right)\left(\Phi\left(x+\delta^{\prime}\right)-\Phi(x+\delta)\right)-\left(\Phi\left(x-\delta^{\prime}\right)-\Phi(x-\delta)\right)\left(\phi\left(x+\delta^{\prime}\right)-\phi(x+\delta)\right)}{\left(\Phi\left(x+\delta^{\prime}\right)-\Phi(x+\delta)\right)^{2}}$.

We will show: $\delta^{\prime}>\delta$ implies that $\Xi^{\prime}(x)>0$ for all $x$. Reversing the inequalities below gives the desired result when $\delta>\delta^{\prime}$.

Observe that $\Xi^{\prime}(x)>0$ if and only if

$-\left(\phi\left(x-\delta^{\prime}\right)-\phi(x-\delta)\right)\left(\Phi\left(x+\delta^{\prime}\right)-\Phi(x+\delta)\right)+\left(\Phi\left(x-\delta^{\prime}\right)-\Phi(x-\delta)\right)\left(\phi\left(x+\delta^{\prime}\right)-\phi(x+\delta)\right)>0$.

Since $\delta^{\prime}>\delta, \Xi^{\prime}(x)>0$ if and only if or if and only if

$$
\frac{\phi\left(x-\delta^{\prime}\right)-\phi(x-\delta)}{\Phi\left(x-\delta^{\prime}\right)-\Phi(x-\delta)}>\frac{\phi(x+\delta)-\phi\left(x+\delta^{\prime}\right)}{\Phi(x+\delta)-\Phi\left(x+\delta^{\prime}\right)}
$$

Applying Cauchy's Mean Value Theorem, there exists $\underline{c} \in\left(x-\delta^{\prime}, x-\delta\right)$ and $\bar{c} \in\left(x+\delta, x+\delta^{\prime}\right)$ such that

$$
\frac{\phi\left(x-\delta^{\prime}\right)-\phi(x-\delta)}{\Phi\left(x-\delta^{\prime}\right)-\Phi(x-\delta)}=\frac{\phi^{\prime}(\underline{c})}{\phi(\underline{c})}
$$

and

$$
\frac{\phi(x+\delta)-\phi\left(x+\delta^{\prime}\right)}{\Phi(x+\delta)-\Phi\left(x+\delta^{\prime}\right)}=\frac{\phi^{\prime}(\bar{c})}{\phi(\bar{c})} .
$$

Observe that $\underline{c}<\bar{c}$ and $\phi$ is log-concave (see Lemma B.1 in Ashworth, Bueno de Mesquita, and Friedenberg, 2017). So

$$
\frac{\phi\left(x-\delta^{\prime}\right)-\phi(x-\delta)}{\Phi\left(x-\delta^{\prime}\right)-\Phi(x-\delta)}=\frac{\phi^{\prime}(\underline{c})}{\phi(\underline{c})}>\frac{\phi^{\prime}(\bar{c})}{\phi(\bar{c})}=\frac{\phi(x+\delta)-\phi\left(x+\delta^{\prime}\right)}{\Phi(x+\delta)-\Phi\left(x+\delta^{\prime}\right)},
$$

implying that $\Xi^{\prime}(x)>0$.

Lemma C.5. There exist some $\bar{x}$ so that $\Delta(\bar{x})=0$.

Proof. Observe that $\Delta(\bar{x})=0$ if and only if $\Xi(\bar{x})=\frac{\left(1-\pi_{I}\right)}{\pi_{I}}$. So it suffices to show that $\Xi(\cdot)$ is onto. To do so, observe that $\Xi(\cdot)$ is continuous. We will show it is not bounded on $\mathbb{R}$, from which it follows that the function is onto. We show this when $\delta^{\prime}>\delta$; a symmetric argument applies for the reverse inequality. 
Observe that, by the Cauchy Mean Value Theorem, for any given $x$, there exists some $\tilde{\delta}(x) \in$ $\left(\delta, \delta^{\prime}\right)$ so that

$$
\Xi(x)=\frac{\phi(x-\tilde{\delta}(x))}{\phi(x+\tilde{\delta}(x))} .
$$

It follows from Lemma A.1 that, when $x \geq 0$ (resp. $x \leq 0$ ), $\Xi(x)$ is greater than or equal to (resp. less than or equal to)

$$
\frac{\phi(x-\delta)}{\phi(x+\delta)}
$$

Now, using the fact that the likelihood ratio is unbounded, for any given $K>0$, there exists some $x(K)$ so that

$$
\Xi(x(K)) \geq \frac{\phi(x(K)-\delta)}{\phi(x(K)+\delta)} \geq K
$$

Likewise, for any given $K<0$. Thus, $\Xi(\cdot)$ is unbounded.

Proof of Lemma C.1. Immediate from Lemmata C.2-C.3-C.4-C.5.

We can apply Lemma C.1 to the functions $\mathcal{N}(g)=\mathcal{G}\left(g-\nu\left(\omega^{\prime}\right), \iota(\omega)\right)$ and $\Gamma\left(g ; \omega^{\prime}\right)=\mathcal{G}(g-$ $\left.\nu\left(\omega^{\prime}\right), \iota\left(\omega^{\prime}\right)\right)$.

Corollary C.1. Suppose disasters amplify the effect of type. If $\omega^{\prime}>\omega$, then there exists some $r$ so that the following hold:

(i) If $g \geq r$, then $\mathcal{N}(g) \geq \Gamma\left(g ; \omega^{\prime}\right)$.

(ii) If $g \leq r$, then $\mathcal{N}(g) \leq \Gamma\left(g ; \omega^{\prime}\right)$.

Corollary C.2. Suppose disasters mute the effect of type. If $\omega^{\prime}>\omega$, then there exists some $r$ so that the following hold:

(i) If $g \geq r$, then $\mathcal{N}(g) \leq \Gamma\left(g ; \omega^{\prime}\right)$.

(ii) If $g \leq r$, then $\mathcal{N}(g) \geq \Gamma\left(g ; \omega^{\prime}\right)$.

Implications for Reelection Probabilities The following Lemmata follow immediately from Corollaries C.1-C.2, the analysis in the main text, and Proposition B.1.

Lemma C.6. Suppose that disasters amplify the effect of type.

(i) If $n \geq r$ and $\pi_{C} \geq \pi_{I}$ with at least one strict inequality, then $1-\Gamma\left(\hat{g}\left(\omega^{\prime}\right), \omega^{\prime}\right)>1-\Gamma(\hat{g}(\omega), \omega)$.

(ii) If $r \geq n$ and $\pi_{I} \geq \pi_{C}$ with at least one strict inequality, then $1-\Gamma(\hat{g}(\omega), \omega)>1-\Gamma\left(\hat{g}\left(\omega^{\prime}\right), \omega^{\prime}\right)$.

Lemma C.7. Suppose that disasters mute the effect of type.

(i) If $r \geq n$ and $\pi_{I} \geq \pi_{C}$ with at least one strict inequality, then $1-\Gamma\left(\hat{g}\left(\omega^{\prime}\right), \omega^{\prime}\right)>1-\Gamma(\hat{g}(\omega), \omega)$.

(ii) If $n \geq r$ and $\pi_{C} \geq \pi_{I}$ with at least one strict inequality, then $1-\Gamma(\hat{g}(\omega), \omega)>1-\Gamma\left(\hat{g}\left(\omega^{\prime}\right), \omega^{\prime}\right)$. 
Where Does $n$ Lie Relative to $r$ We begin with a preliminary result that will be of use.

Lemma C.8. There is an $\tilde{\omega} \in\left(\omega, \omega^{\prime}\right)$ such that

$$
\frac{\phi\left(r-\nu\left(\omega^{\prime}\right)-\iota(\tilde{\omega})\right)}{\phi\left(r-\nu\left(\omega^{\prime}\right)+\iota(\tilde{\omega})\right)}=\frac{1-\pi_{I}}{\pi_{I}} .
$$

Proof. By Lemmata C.2-C.3,

$$
-\frac{\Phi\left(r-\nu\left(\omega^{\prime}\right)-\iota\left(\omega^{\prime}\right)\right)-\Phi\left(r-\nu\left(\omega^{\prime}\right)-\iota(\omega)\right)}{\Phi\left(r-\nu\left(\omega^{\prime}\right)+\iota\left(\omega^{\prime}\right)\right)-\Phi\left(r-\nu\left(\omega^{\prime}\right)+\iota(\omega)\right)}=\frac{1-\pi_{I}}{\pi_{I}} .
$$

Applying the Cauchy Mean Value Theorem to the functions given by

$$
h_{-}(x) \equiv \Phi\left(r-\nu\left(\omega^{\prime}\right)-\iota(x)\right) \quad \text { and } \quad h_{+}(x) \equiv \Phi\left(r-\nu\left(\omega^{\prime}\right)+\iota(x)\right) \text {, }
$$

we see that there exists some $\tilde{\omega} \in\left(\omega, \omega^{\prime}\right)$ such that

$$
-\frac{\Phi\left(r-\nu\left(\omega^{\prime}\right)-\iota\left(\omega^{\prime}\right)\right)-\Phi\left(r-\nu\left(\omega^{\prime}\right)-\iota(\omega)\right)}{\Phi\left(r-\nu\left(\omega^{\prime}\right)+\iota\left(\omega^{\prime}\right)\right)-\Phi\left(r-\nu\left(\omega^{\prime}\right)+\iota(\omega)\right)}=\frac{\phi\left(r-\nu\left(\omega^{\prime}\right)-\iota(\tilde{\omega})\right)}{\phi\left(r-\nu\left(\omega^{\prime}\right)+\iota(\tilde{\omega})\right)} .
$$

From this the claim follows.

In light of Lemma C.8, in all subsequent results, we fix $\tilde{\omega} \in\left(\omega, \omega^{\prime}\right)$ so that

$$
\frac{\phi\left(r-\nu\left(\omega^{\prime}\right)-\iota(\tilde{\omega})\right)}{\phi\left(r-\nu\left(\omega^{\prime}\right)+\iota(\tilde{\omega})\right)}=\frac{1-\pi_{I}}{\pi_{I}} .
$$

Lemma C.9. Fix $\omega^{\prime}>\omega$.

(i) If $\pi_{I} \geq \frac{1}{2}$, then $r \leq \nu\left(\omega^{\prime}\right)$.

(ii) If $\pi_{I} \leq \frac{1}{2}$, then $r \geq \nu\left(\omega^{\prime}\right)$.

Proof. We show that $r \leq \nu\left(\omega^{\prime}\right)$ if and only if $\pi_{I} \geq \frac{1}{2}$. Reversing the inequalities gives that $r \geq \nu\left(\omega^{\prime}\right)$ if and only if $\pi_{I} \leq \frac{1}{2}$.

Observe that $r \leq \nu\left(\omega^{\prime}\right)$ if and only if

$$
1=\frac{\phi\left(\nu\left(\omega^{\prime}\right)-\nu\left(\omega^{\prime}\right)-\iota(\tilde{\omega})\right)}{\phi\left(\nu\left(\omega^{\prime}\right)-\nu\left(\omega^{\prime}\right)+\iota(\tilde{\omega})\right)} \geq \frac{\phi\left(r-\nu\left(\omega^{\prime}\right)-\iota(\tilde{\omega})\right)}{\phi\left(r-\nu\left(\omega^{\prime}\right)+\iota(\tilde{\omega})\right)}=\frac{1-\pi_{I}}{\pi_{I}}
$$

where the first equality follows from symmetry, the second inequality follows from the MLRP, and the last equality is by Lemma C.8. It follows that $r \leq \nu\left(\omega^{\prime}\right)$ if and only if $\pi_{I} \geq \frac{1}{2}$.

\section{Lemma C.10.}

(i) $n \leq \nu\left(\omega^{\prime}\right)$ if and only if $\pi_{I} \geq \pi_{C}$.

(ii) $n \geq \nu\left(\omega^{\prime}\right)$ if and only if $\pi_{C} \geq \pi_{I}$ 
Proof. Note that $n \leq \nu\left(\omega^{\prime}\right)$ if and only if

$$
1=\frac{\phi\left(\nu\left(\omega^{\prime}\right)-\nu\left(\omega^{\prime}\right)-\iota(\omega)\right)}{\phi\left(\nu\left(\omega^{\prime}\right)-\nu\left(\omega^{\prime}\right)+\iota(\omega)\right)} \geq \frac{\phi\left(n-\nu\left(\omega^{\prime}\right)-\iota(\omega)\right)}{\phi\left(n-\nu\left(\omega^{\prime}\right)+\iota(\omega)\right)}
$$

where the inequality follows from the MLRP and the equality follows from symmetry. Using the fact that

$$
\frac{\phi\left(n-\nu\left(\omega^{\prime}\right)-\iota(\omega)\right)}{\phi\left(n-\nu\left(\omega^{\prime}\right)+\iota(\omega)\right)}=\frac{\phi(\hat{g}(\omega)-\nu(\omega)-\iota(\omega))}{\phi(\hat{g}(\omega)-\nu(\omega)+\iota(\omega))}=\frac{1-\pi_{I}}{\pi_{I}} \frac{\pi_{C}}{1-\pi_{C}}
$$

it follows that $n \leq \nu\left(\omega^{\prime}\right)$ if and only if

$$
1 \geq \frac{1-\pi_{I}}{\pi_{I}} \frac{\pi_{C}}{1-\pi_{C}}
$$

or if and only if $\pi_{I} \geq \pi_{C}$. Reversing the inequalities gives part (ii).

\section{Lemma C.11.}

(i) Suppose that $\pi_{C} \geq \pi_{I} \geq \frac{1}{2}$ with at least one strict inequality. Then $n>r$.

(ii) Suppose that $\frac{1}{2} \geq \pi_{I} \geq \pi_{C}$ with at least one strict inequality. Then $r>n$.

Proof. We show part (i); part (ii) follows by reversing inequalities: By Lemma Lemma C.10(i), $\pi_{C} \geq \pi_{I}$ (resp. $\pi_{C}>\pi_{I}$ ) implies $n \geq \nu\left(\omega^{\prime}\right)$ (resp. $n>\nu\left(\omega^{\prime}\right)$ ). By Lemma C.9, $\pi_{I} \geq \frac{1}{2}$ (resp. $\pi_{I}>\frac{1}{2}$ ) implies $\nu\left(\omega^{\prime}\right) \geq r$ (resp. $\nu\left(\omega^{\prime}\right)>r$ ). Thus, if $\pi_{C} \geq \pi_{I} \geq \frac{1}{2}$ with at least one inequality, then $n \geq \nu\left(\omega^{\prime}\right) \geq r$ with at least one strict inequality.

Lemma C.12. Fix $\omega^{\prime}>\omega$ and suppose that disasters amplify the effect of type. If $\pi_{C} \geq \frac{1}{2} \geq \pi_{I}$, then $n \geq r$.

Proof. Observe that

$$
\begin{aligned}
\frac{\phi\left(r-\nu\left(\omega^{\prime}\right)-\iota(\tilde{\omega})\right)}{\phi\left(r-\nu\left(\omega^{\prime}\right)+\iota(\tilde{\omega})\right)} & =\frac{1-\pi_{I}}{\pi_{I}} \\
& \leq \frac{1-\pi_{I}}{\pi_{I}} \frac{\pi_{C}}{1-\pi_{C}} \\
& =\frac{\phi(\hat{g}(\omega)-\nu(\omega)-\iota(\omega))}{\phi(\hat{g}(\omega)-\nu(\omega)+\iota(\omega))} \\
& =\frac{\phi\left(n-\nu\left(\omega^{\prime}\right)-\iota(\omega)\right)}{\phi\left(n-\nu\left(\omega^{\prime}\right)+\iota(\omega)\right)} .
\end{aligned}
$$

where the first line follows from Lemma C.8, second line follows from the fact that $\pi_{C} \geq \frac{1}{2}$, the third line follows from the definition of $\hat{g}(\omega)$, and the last line follows from the definition of $n$.

With this, to show that $n \geq r$, it suffices to show that

$$
\frac{\phi\left(r-\nu\left(\omega^{\prime}\right)-\iota(\tilde{\omega})\right)}{\phi\left(r-\nu\left(\omega^{\prime}\right)+\iota(\tilde{\omega})\right)} \geq \frac{\phi\left(r-\nu\left(\omega^{\prime}\right)-\iota(\omega)\right)}{\phi\left(r-\nu\left(\omega^{\prime}\right)+\iota(\omega)\right)} .
$$


In that case, the inequalities above imply that

$$
\frac{\phi\left(n-\nu\left(\omega^{\prime}\right)-\iota(\omega)\right)}{\phi\left(n-\nu\left(\omega^{\prime}\right)+\iota(\omega)\right)} \geq \frac{\phi\left(r-\nu\left(\omega^{\prime}\right)-\iota(\omega)\right)}{\phi\left(r-\nu\left(\omega^{\prime}\right)+\iota(\omega)\right)}
$$

From this, the MLRP implies that $n \geq r$, as desired.

By Lemma C.9 and the fact that $\frac{1}{2} \geq \pi_{I}, r \geq \nu\left(\omega^{\prime}\right)$. With this, the function

$$
\delta \mapsto \frac{\left.\phi\left(r-\nu\left(\omega^{\prime}\right)-\delta\right)\right)}{\left.\phi\left(r-\nu\left(\omega^{\prime}\right)+\delta\right)\right)}
$$

is (weakly) increasing in $\delta$. (See Lemma A.1.) Now using the fact that disaster amplifies the effect of type, it follows that $\iota(\tilde{\omega})>\iota(\omega)$. From this, Equation (10) follows.

Reversing the argument in the proof of Lemma C.12, we get the following:

Lemma C.13. Fix $\omega^{\prime}>\omega$ and suppose that disasters amplify the effect of type. If $\pi_{I} \geq \frac{1}{2} \geq \pi_{C}$, then $r \geq n$.

Conclusion of Proof Proposition C.1 follows from Lemmata C.6, Lemma C.11 Lemma C.12, and Lemma C.13. Proposition C.2 follows from Lemmata C.7, Lemma C.11 and the following two additional results.

Lemma C.14. Suppose disasters mute the effect of type and $\pi_{I}>\frac{1}{2} \geq \pi_{C}$. Then $\Gamma(\hat{g}(\omega), \omega)>$ $\Gamma\left(\hat{g}\left(\omega^{\prime}\right), \omega^{\prime}\right)$.

Proof. If $r \geq n$, then Lemma C.7 says that $\Gamma(\hat{g}(\omega), \omega)>\Gamma\left(\hat{g}\left(\omega^{\prime}\right), \omega^{\prime}\right)$. Suppose that $n>r$. We will show that $r>\hat{g}\left(\omega^{\prime}\right)$. With this,

$$
\Gamma(\hat{g}(\omega), \omega)=\mathcal{N}(n)>\mathcal{N}(r)=\Gamma\left(r, \omega^{\prime}\right)>\Gamma\left(\hat{g}\left(\omega^{\prime}\right), \omega^{\prime}\right)
$$

where the first inequality follows from the assumption that $n>r$ and the MLRP, the second equality follows by Corollary C.2, and the last inequality follows from the fact that $r>\hat{g}\left(\omega^{\prime}\right)$ (that we will show) and the MLRP.

We now turn to show that $r>\hat{g}\left(\omega^{\prime}\right)$ : By Lemma C.8, there exists some $\tilde{\omega} \in\left(\omega, \omega^{\prime}\right)$ so that

$$
\frac{\phi\left(r-\nu\left(\omega^{\prime}\right)-\iota(\tilde{\omega})\right)}{\phi\left(r-\nu\left(\omega^{\prime}\right)+\iota(\tilde{\omega})\right)}=\frac{1-\pi_{I}}{\pi_{I}}
$$

Since disaster mutes the effect of type, $\iota(\omega)>\iota(\tilde{\omega})>\iota\left(\omega^{\prime}\right)$. Moreover, since $\pi_{I}>\frac{1}{2}$, Lemma C.9 implies that $r-\nu\left(\omega^{\prime}\right)<0$. Thus, applying Lemma A.1,

$$
\frac{\phi\left(r-\nu\left(\omega^{\prime}\right)-\iota\left(\omega^{\prime}\right)\right)}{\phi\left(r-\nu\left(\omega^{\prime}\right)+\iota\left(\omega^{\prime}\right)\right)}>\frac{\phi\left(r-\nu\left(\omega^{\prime}\right)-\iota(\tilde{\omega})\right)}{\phi\left(r-\nu\left(\omega^{\prime}\right)+\iota(\tilde{\omega})\right)}=\frac{1-\pi_{I}}{\pi_{I}} .
$$


Since $\frac{1}{2} \geq \pi_{C}$, this implies that

$$
\frac{\phi\left(r-\nu\left(\omega^{\prime}\right)-\iota\left(\omega^{\prime}\right)\right)}{\phi\left(r-\nu\left(\omega^{\prime}\right)+\iota\left(\omega^{\prime}\right)\right)}>\frac{1-\pi_{I}}{\pi_{I}} \frac{\pi_{C}}{1-\pi_{C}}=\frac{\phi\left(\hat{g}\left(\omega^{\prime}\right)-\nu\left(\omega^{\prime}\right)-\iota\left(\omega^{\prime}\right)\right)}{\phi\left(\hat{g}\left(\omega^{\prime}\right)-\nu\left(\omega^{\prime}\right)+\iota\left(\omega^{\prime}\right)\right)} .
$$

So by the MLRP $r>\hat{g}\left(\omega^{\prime}\right)$.

Reversing the inequalities in the proof of Lemma C.14 gives the following:

Lemma C.15. Suppose disasters mute the effect of type and $\pi_{C}>\frac{1}{2} \geq \pi_{I}$. Then $\Gamma\left(\hat{g}\left(\omega^{\prime}\right), \omega^{\prime}\right)>$ $\Gamma(\hat{g}(\omega), \omega)$. 